\title{
Pharmacogenetic inhibition of the subcoeruleus region influences REM sleep and cataplexy in narcoleptic mice
}

by

Karan Paul Sanghera

A thesis submitted in conformity with the requirements for the degree of Masters of Science

Graduate Department of Cell and Systems Biology

University of Toronto

(C) Copyright by Karan Paul Sanghera 2013 


\title{
Pharmacogenetic inhibition of the subcoeruleus region
}

\section{influences REM sleep and cataplexy in narcoleptic mice}

\author{
Master of Science, 2013 \\ Karan Paul Sanghera \\ Graduate Department of Cell and Systems Biology \\ University of Toronto
}

Introduction: Cataplexy - the sudden involuntary loss of skeletal muscle tone - is a defining feature of narcolepsy. The current study aimed to determine if cataplexy is influenced by direct manipulation of REM sleep circuitry. We did this by pharmacogenetically inhibiting the REM sleep centre, subcoeruleus (Sub-C).

Methods: Inhibitory DREADD (hM4D-Gi) was bilaterally targeted to the Sub-C in hypocretin knockout mice $(\mathrm{n}=7)$. Intraperitoneal administration of clozapine-n-oxide was used to inhibit Sub-C cells expressing hM4D-Gi. Electrophysiological and behavioural criteria were used to characterize cataplexy and REM sleep.

Results: Sub-C inhibition increased REM sleep and cataplexy amounts $(\mathrm{p}<0.05)$. Sub-C inhibition increased time spent in cataplexy amounts by increasing the number of cataplexy attacks $(\mathrm{p}<0.05)$. This intervention triggered increases in basal muscle tone during REM sleep, but had negligible effects on muscle tone during cataplexy ( $\mathrm{p}>0.05)$. 
Conclusion: Pharmacogenetic manipulation of the Sub-C suggest that REM sleep and cataplexy are mediate by similar neural mechanism. 


\section{Acknowledgements}

It is with great pleasure and gratitude that I would like to thank everyone who has helped me along the path of conducting my masters research. I am thankful for the contributions and suggestions made by my advisory committee members, Dr. Richard Stephenson, Dr. Junchul Kim, and Dr. Kaori Takehara-Nishiuchi, your insight has been thought-provoking and has aided me greatly in the completion of my project.

I would like to thank Dr. John Peever for giving me the opportunity to work under his supervision to conduct research that has been both fascinating and challenging. John, your passion for sleep research is contagious and you will always be a model for me as a scientist and professional. Working with you these last few years has helped me develop into a more critical thinker and better communicator. I am also grateful for the amazing group of trainees you brought together in your lab.

My labmates are some of the most intelligent and hard-working people I have ever met. I have learned so much from all of them, and could not have completed this project without their support and guidance. To the senior members of the lab (Jimmy, Peter, Jenn, Nicole, Arash and Christian), your expertise has helped me develop into a better scientist, young professional, and even a better cook. I can't say enough to thank you for all of your help. Zoltan, you have been like a brother to me during my time in the lab. You have no idea how much your friendship and support has meant to me. I will miss travelling with you and all of our late nights philosophizing. To the dynamic duo Sharshi and Daniel, you guys have always been there as helping hand; I appreciate everything you have done for me inside the lab, and out. You all have made these last two years a truly unforgettable experience filled with laughter and memories and I wish you happiness and great success in all future endeavors you pursue.

Finally, I would like to thank my family and friends for their constant support and unconditional love over what seems like my endless schooling. To my best friend and girlfriend Michelle, I'm sorry for the endless conversations about the minutia of the neurobiology of sleep in mice, but thank you for always pretending to be interested. I could not have done this without your unwavering support, and I thank you for being by my side through it all. 


\section{Table of Contents}

Abstract

Acknowledgements

Table of Contents

List of Figures

Chapter 1: Introduction

1.1 Overview

1.2 REM Sleep Generation

1.2.1 Reciprocal aminergic-cholinergic interaction model

1.2.2 Glutamatergic-GABAergic reciprocal flip-flop switch 5

1.3 REM sleep atonia

1.4 Narcolepsy

1.5 Cataplexy

1.6 Neurobiology of Cataplexy

1.6.1 GABAergic mechanisms in cataplexy 11

$\begin{array}{ll}\text { 1.6.2 Cholinergic mechanisms in cataplexy } & 11\end{array}$

1.6.3 Monoaminergic mechanisms of cataplexy 12

1.7 Do REM sleep and cataplexy share a common mechanism? 13

1.8 DREADDs

1.8.1 Properties of Clozapine-N-Oxide

Chapter 2: $\quad$ Aims

$\begin{array}{lll}\text { Chapter 3: } & \text { Methods } & 19\end{array}$

3.1 Animals 19

3.2 Viral transduction $\quad 19$

3.3 Surgery/ Experimental protocol 21

3.4 Drugs and administration $\quad 22$

$\begin{array}{ll}3.5 \text { Data acquisition } & 22 \\ 3.6 & \text { Bilateral SubC HMLDinjection }\end{array}$

3.6 Bilateral SubC HM4Di injection 23

3.7 Bilateral SubC viral control injection 23

3.8 Histological confirmation of viral targeting to the SubC 23

$\begin{array}{lll}3.9 & \text { Data analysis } & 24\end{array}$

3.10 REM sleep and cataplexy EMG analysis $\quad 24$

3.11 REM sleep and cataplexy EEG spectral analysis $\quad 25$

$\begin{array}{ll}3.12 \text { Statistical analysis } & 26\end{array}$

$\begin{array}{lll}\text { Chapter 4: } & \text { Results } & 28\end{array}$

4.1 Viral transgenes were targeted to the SubC region 28

4.2 CNO without HM4di does not alter sleep-wake architecture 28

4.3 Changes to sleep-wake architecture were not due to handling or i.p injection 28

4.4 Inhibiting the SubC leads to changes to sleep-wake architecture up to two and a 32 half hours post CNO injection

4.5 Inhibiting the SubC leads to an increase in REM sleep 
4.6 Inhibiting the SubC increases fragmentation of sleep-wake cycle 39

4.7 Inhibiting the SubC leads to a decrease in cataplexy 39

4.8 Inhibiting the SubC leads to a loss of normal muscle tone suppression during 42

REM sleep, but not cataplexy.

4.9 Inhibiting the SubC does not alter muscle tone in Wake or NREM

4.10 Inhibiting the SubC leads to greater cortical theta during REM sleep

Chapter 5: Discussion

5.1 Overview

5.2 Do cataplexy and REM share common mechanism?

54

5.3 Technical limitations and future directions

55

5.4 Concluding remarks

Chapter 5: $\quad$ References 


\section{List of Tables}

Table 1 Schematic representing the proposed circuitry underlying the role of the SubC in the cortical and motor atonia aspects of REM sleep

Table 2 Physiological criteria of cataplexy differ from physiological changes characteristic of REM sleep, suggesting they may not share a common mechanism

Table 3 Sleep wake architecture under baseline, saline injection, and CNO $(10 \mathrm{mg} / \mathrm{kg})$ 35 injection 


\section{List of Figures}

Figure $1 \quad$ Representative electrophysiological traces of REM sleep and cataplexy $\quad 8$

$\begin{array}{lll}\text { Figure } 2 & \text { Schematic of adeno-associated vectors } & 20\end{array}$

Figure 3 Histological confirmation of hSyn-EGFP transduction in the region of the 29 SubC.

Figure 4 Histological confirmation of HM4di transduction in the region of the 30 SubC.

Figure 5 CNO $(10 \mathrm{mg} / \mathrm{kg})$ does not alter sleep-wake architecture in animals lacking 31 viral HM4di incorporation.

Figure 6 Intraperitoneal injection of saline does not affect sleep wake architecture 33 compared to baseline.

Figure 7 The effect of CNO $(10 \mathrm{mg} / \mathrm{kg})$ injection on REM sleep architecture over the first three hours post-injection.

Figure 8 Inhibition of the SubC leads to alterations of sleep-wake architecture over 37 the first two hours of the dark phase (19:00-21:00h).

Figure 9 SubC inhibition leads to increases the propensity towards REM sleep.

Figure 10 Under SubC inhibition NREM sleep preferentially transitions into REM sleep at the expense of wake.

Figure 11 There is an overall decrease in cataplexy which can be accounted for by 41 the decrease in total wake.

Figure 12 Inactivation of the SubC leads to REM sleep specific changes to motor tone (a loss of REM sleep atonia).

Figure 13 SubC inhibition has causes a loss of atonia in REM sleep, but not during Cataplexy.

Figure 14 Inhibition of the SubC does not alter the stereotypic motor profile of cataplexy.

Figure 15 Inhibition of SubC does not alter motor profile outside of REM sleep.

Figure 16 Inhibiting the SubC leads to profound changes cortical power spectrum during REM sleep. 


\section{Section 1 - Introduction}

\section{Section 1.1 - Overview}

The function of sleep is an enduring mystery of modern neuroscience. No succinct theory has provided an evolutionary, physiological or behavioural rationale for the universal phenomenon of sleep. Although the reason we sleep has yet to be uncovered, great thinkers over the last century have shed light on the mechanisms which mediate our entry into, and exit from sleep. Each step in understanding how we sleep brings science closer to understanding its purpose.

In 1915, Baron Constantin von Economo, a neurologist from Vienna, studied a number of patients with viral encephalitis presenting with sleep-related ailments. Many of these patients experienced lethargy, while others presented with insomnia. After the encephalitis bout subsided, a number of patients suffered from strange sleep attacks. von Economo described these sleep attacks as "the dissociation of the cerebral and body sleep observed in a series of akinetic cases, patients being in day time mentally wide awake while their bodies were akinetic and drowsy as in sleep.” [1] What he was describing here was the phenomenon of cataplexy, a symptom of narcolepsy, characterized by muscle paralysis associated with waking cortical activity.

In 1930, von Economo published the seminal paper "Sleep as a Problem of Localization”. This paper provided histological insight into the neurological underpinnings for the dysfunctions reported in patients. Patients who experienced difficulties maintaining sleep had lesions at the junction of the midbrain and the diencephalon, whereas patients who suffered from insomnia had lesions in the preoptic area. Lastly the patients who displayed narcolepsy had 
lesions in the lateral and posterior hypothalamus [1]. A neurological basis for narcolepsy and sleep control had been discovered.

Narcolepsy was originally described by Westphal and Gelineau at the end of the 19th century. Narcolepsy was defined by pronounced fragmentation of wakefulness and disrupted night-time sleep. However the most striking symptom was cataplexy, the intrusion of the REM sleep muscle paralysis into wakefulness. To illustrate the severity of these cataplectic attacks below is a description of a Cataplexy by Westphal.

"During these attacks, he was unable to raise his arms. If the attack came upon him while walking or standing, he had to find some means of support, although a cane was sufficient for the purpose. These attacks varied in duration, depending on whether he had exerted himself beforehand. He did not lose consciousness during these attacks. He understood everything when spoken to; he was simply unable to respond coherently or fluently" - [2]

As observed in von Economos' encephalitis patients, narcolepsy is highly associated with disruption of a small cluster of neurons in the lateral and posterior hypothalamus. The effected neurons produce the peptide hypocretin (also called orexin), and innervate brain areas that house cholinergic, monoaminergic and other cell groups which function to promote wakefulness [3]. The general understanding is that the hypothalamic hypocretin system strengthens and consolidates wake; however details of the neuronal dysfunctions which lead to narcolepsy and its symptoms are mostly unknown.

This thesis aims to investigate the relationship between REM sleep circuitry and Narcolepsy. Von Economos' description of narcolepsy as "the dissociation of the cerebral and body sleep" has endured and shaped our modern conceptualization that cataplexy is simply the intrusion of the REM sleep into waking [4, 5]. I will begin with a brief account of the research 
which has formed our conceptions of REM sleep and its neurobiological underpinnings. Special attention will be given to REM sleep atonia, the loss of muscle tone observed during REM sleep. As REM sleep atonia and cataplexy are believed to share neural circuitry. I will then describe the fields current understanding of neurological mechanisms affected by cataplexy.

\section{Section 1.2 - REM Sleep Generation}

In the early 1950’s sleep was found to not be a singular homogenous state. At the University of Chicago, Eugene Aserinsky and Nathaniel Kleitman discovered a subtype of sleep. This period possessed a stereotypic pattern of wake like cortical activity, muscle atonia punctuated with twitches, and rapid eye movements [6]. This period was postulated as the stage in which dreaming occurs. This stage has gone on to be named rapid eye movement (REM) sleep, active sleep or paradoxical sleep. Over the next decade the search for the neurological region controlling REM sleep intensified. Unlike von Economos’ encephalitis, the neural mechanism initiating this subtype of sleep did not arise in the midbrain, but in the brainstem[7]. These early findings set the stage for our understanding of the neurocircuitry which controls our sleep and wake. Since the mid-20 $0^{\text {th }}$ century we have come to find a number of wake-active and sleep-active neurons, which are hypothesized to both generate and regulate REM sleep.

In Jouvet and Michel’s seminal paper, REM generating circuits were localized to the pontomedulluary region. REM sleep remained intact after transections of brainstem rostral of the pons. However transections at the pontomedullary border eliminated signs of REM sleep[7]. These early findings implicated the pontine region of the brainstem as the seat of REM sleep in the brain. Subsequent studies using neurotoxic lesioning, pharmacological interventions, and Fos staining refined the understanding by implicating a specific pontine cell population, in rodents an area named the sublaterodorsal nucleus (SubC), as the point of induction and 
maintenance of REM sleep and REM sleep atonia [8-11]. The SubC is a small pontine nucleus representing a mix of glutamateric and GABAergic neurons; located ventral to the locus coeruleus (LC), medial to the trigeminal motor nucleus (MO5) and ventromedial to the laterodorsal tegmental nucleus (LDT) and the parabrachial nucleus (PB).

It has been established that the SubC contains at least two populations of neurons critical for the manifestation of REM sleep. A matter of contention has been which neurotransmitter systems act on the SubC leading to the onset and maintenance of REM sleep. Empirical evidence has supported two theories of REM sleep control; first the reciprocal aminergiccholinergic interaction, and more recently the GABAergic-glutamatergic flip-flop switch.

\section{Section 1.2.1 - Reciprocal Aminergic-Cholinergic Interaction Model}

In 1975 Hobson, McCarley and Wyzinski proposed the reciprocal aminergic-cholinergic interaction model of REM sleep[12]. Based on sleep-cycle dependent changes to neuronal discharge rates, Hobson and colleagues hypothesized a reciprocal inhibitory interaction between REM-ON cholinergic neurons and REM-off monoaminergic neurons. It was observed that the firing rates of noradrenergic neurons of the locus coereulus (LC) and the serotonergic neurons of the dorsal raphe nucleus (DRN) fell silent during REM sleep. Cholinergic neurons, of the laterodorsal tegmentum and pedunculopontine tegmentum (LDT/PPT) on the other hand were most active during REM sleep, as well as waking. Subsequent pharmacological findings generally supported acetylcholine and its agonists as REM sleep promoting and noradrenaline and serotonin and their agonists as REM sleep suppressing; with most support in cats and mixed findings in rats [13-15]. As a results carbachol (ACh agonist) injections into the pontomedullary region (SubC) have become a widely studied as model for REM sleep [16-20]. Using the carbachol model of REM sleep in cats, Kazuya Sakai of the University of Lyon in 
France divided the SubC into two populations. The first population was excited by carbachol, projected caudally to the ventral gigantocellular nucleus (GiV) and is thought to be responsible to the motor atonia observed during REM sleep [21, 22]. The second population was inhibited by carbachol and projected rostrally to the thalamus, posterior hypothalamus and basal forebrain. This population is thought to be responsible for the cortical activation observed during REM sleep. This work was later confirmed in rats, where it was shown that this second population was shown to represent $40 \%$ of SubC neurons. These neurons were silent at rest and hyperpolarized by carbachol. However at the offset of hyperpolarizations these neurons and fired in bursts of several action potentials [23].

The cholinergic-monoaminergic model of REM sleep has been well supported, but it is not without its limitations. Pharmacological findings have brought into question the reciprocal inhibitory interaction between these two groups, as injection of acetylcholine did not inhibit the noradrenergic LC or the serotonergic DR[24, 25]. Also, neurological tracing do not connect cholinergic groups to other critical REM centres such as the ventral gigantocellular reticular nucleus (GiV), a group critical to REM sleep atonia [26]. Last, lesions of the cholinergic LDT/PPT in rats did not change amounts of REM sleep [11]. From these findings it is clear that the onset and maintenance of REM sleep is due at least in part cholinergic and monoaminergic mechanisms.

Section 1.2.2 - Glutamatergic-GABAergic Reciprocal flip-flop switch

To account for the limitations of the reciprocal aminergic-cholinergic interaction model of REM sleep, the field shifted focus to a glutamatergic-GABAergic model of REM sleep. GABAergic neurons critical to REM sleep have been broadly classified into two main groups, REM-off and REM-on GABA neurons. REM-off GABA neurons are postulated to prevent 
activation of REM-on reticular neurons, such as those of the SubC, during wakefulness and NREM sleep. These neurons are called REM-off because they do not fire during REM sleep, creating an environment which is conducive for REM sleep. On the other hand, REM-on GABA neurons, are active during REM sleep and are postulated to play a role in inhibiting the activity of aminergic neurons.

In the mid 2000’s it was theorized that the control of REM sleep entry was under the control of a reciprocal flip-flop switch [11]. The flip-flop switch model consists of mutually inhibitory projections between the GABAergic REM-off venterolateral periaqueductal gray (vlPAG) and GABAergic neurons of the REM-on SubC. The vlPAG is active during wake where it suppresses SubC activity. Providing evidence for this theory, GABAergic inputs have been shown to project onto the SubC from the vlPAG [10, 11, 27]. Pharmacological studies have shown that the REM-on SubC neurons are activated by glutamate and inhibited by GABA[10].

This model accounts for why normally REM sleep is occurs only after NREM sleep. During NREM sleep the VLPAG is inhibited by an outside structure, proposed to be the sleep active GABAergic neurons of the ventrolateral preoptic area (VLPO) and the Melaninconcentrating hormone $(\mathrm{MCH})$ neurons of the lateral hypothalamus[28]. Once the vlPAG is inhibited, the SubC is disinhibited, making entry into REM sleep more conducive[11]. How the SubC regulates the timing or exact entry into REM sleep is up to debate. What remains unknown is the nature of the excitatory inputs onto the SubC. It has been postulated that there is a persistent glutamatergic drive onto the SubC of unknown origin [27]. 
Section 1.3 - REM Sleep Atonia

Muscle activity follows a stereotypic patter across the sleep-wake cycle; activity is the highest during wakefulness, lowered in NREM (non-REM sleep), and lowest during REM sleep. Muscle tone during REM sleep is described as atonic (without tone), with brief phasic muscle twitches (figure 1). The early transection studies mentioned above were used to localize the neural groups responsible for REM sleep atonia to the rostral area of the pons[7]. It has since been well established that connections between the pons and groups of the medial medulla play contribute to REM sleep atonia [5]. Lesion and pharmacological studies pointed to the SubC as the pontine group critical to REM sleep [11, 29].

The downstream projections of the SubC point to a role in the maintenance of REM sleep atonia. Anterograde tracing studies have shown that one subset of glutamatergic SubC REM-on neurons have projections downstream to the alpha and ventral gigantocellular (GiA/GiV) neurons as well as spinal interneurons of the ventral horn[10]. These descending pathways have been shown to play a role in REM atonia [30, 31]. The alpha and ventral gigantocellular (GiA/GiV) neurons are a population of inhibitory pre-motor neurons, which project onto cranial and spinal motor pools [31]. Activation of these GABA/glycine containing neurons causes direct inhibition onto the motor pools leading to atonia. The spinal interneurons act in the same way, upon activation by the SubC; the spinal interneurons release GABA and glycine onto the spinal motor pools leading to atonia loss of postural muscles [11]. A summary of the postulated neurocircuitry of the SubC is provided in table 1.

Much of the published behavioral work on the SubC in rodents originate from Jun Lu's group at Harvard medical school. In 2010, they demonstrated that lesions of the SubC lead to differential changes to atonia depending on the muscle studied. Lesions of the SubC lead to 

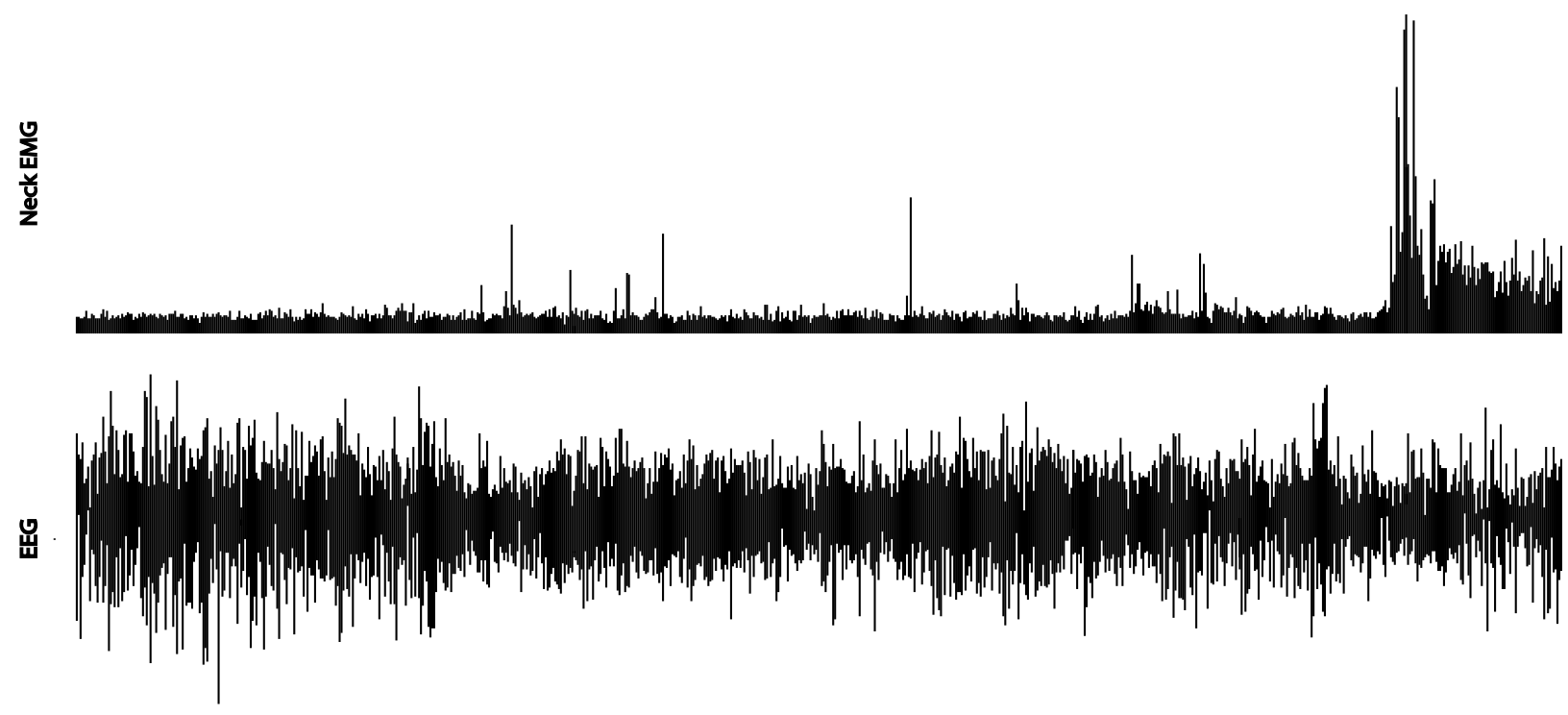

B
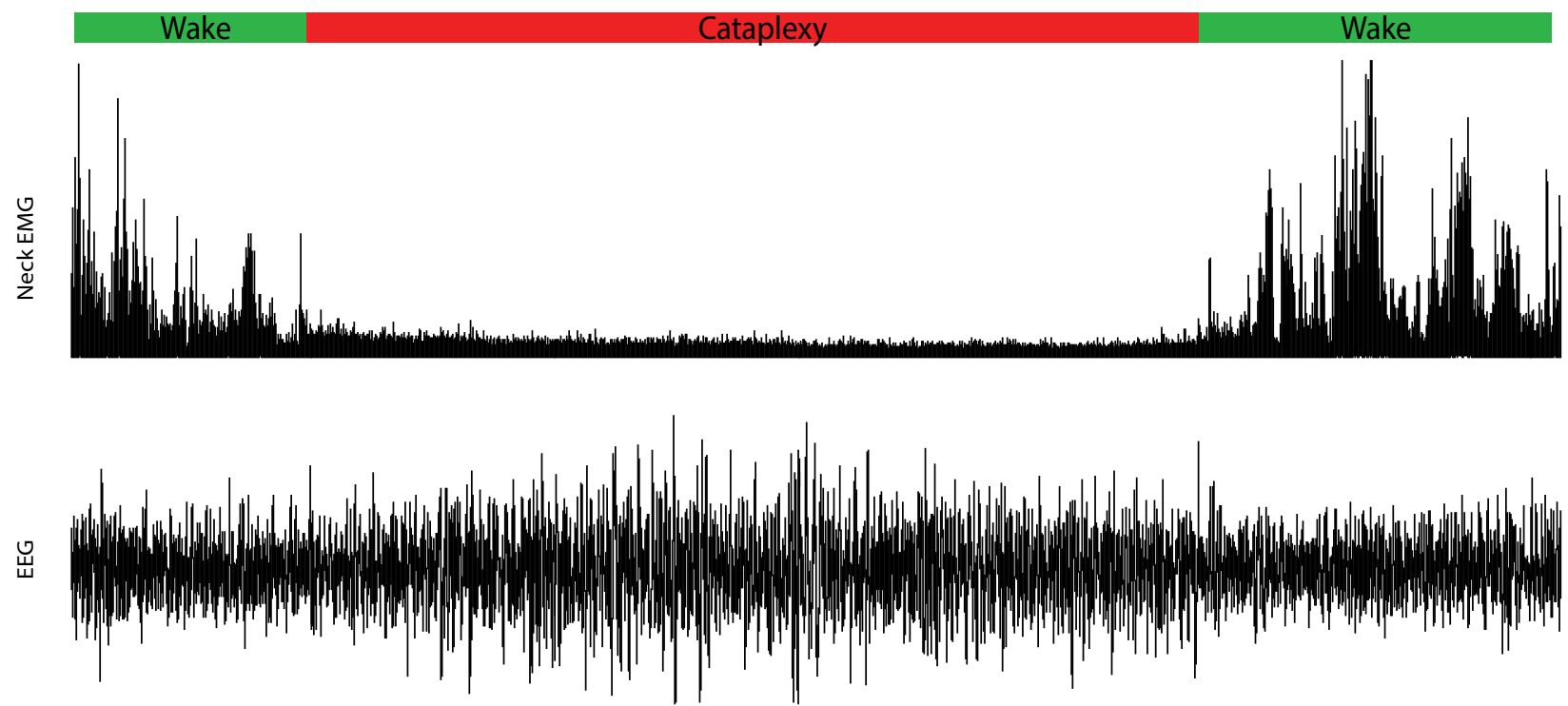

Figure 1 - Representative electrophysiological traces of REM sleep and cataplexy. A) A raw eletrophysiological trace of a typical REM sleep period. REM sleep is almost always preceded by a period of NREM sleep, and followed by wakefulness. Top, a raw EMG trace of the neck muscle which displays the stereotypic REM sleep atonia punctuated by phasic twitches. Bottom, a raw EEG trace which shows the characteristic low amplitude high frequency cortical activity during REM sleep. B) A raw electrophysiological trace of a typical cataplexy period. Top, a raw EMG trace of the neck muscle which displays the loss of muscle tone during the cataplectic attack. Bottom, a raw EEG trace which shows the characteristic high frequency cortical activity during a cataplectic attack. 
increased tonic motor tone during REM sleep and an increase in the phasic activity in the neck, but not in the masseter [30]. This finding indicates that the downstream projections of the SUBC which lead to atonia may have a larger effect on spinal interneurons of postural muscles, rather than cranial motor nuclei (such as the trigeminal motor nucleus). The following year, Lu’s group ablated glutamatergic transmission in the SubC lead to a RBD-like phenotype [32]. These behavioural and neural tracing studies have substantiated the hypothesis that the SubC is a “gatekeeper” of muscle atonia.

\section{Section 1.4 - Narcolepsy}

Narcolepsy consists of four major symptoms: (1) excessive daytime sleepiness, (2) cataplexy, (3) sleep paralysis, (4) hypnagogic hallucinations [33]. Epidemiological studies indicate narcolepsy has a prevalence of approximately 1 in 2000 individuals [33], of which approximately 70\% display cataplexy [34]. The cluster of symptoms associated with narcolepsy can be conceived as an uncoupling of motor and cortical control leading to mixed behaviour states. For instance hypnagogic hallucinations, which are hallucinations occurring around sleep onset or awakening is conceived as REM sleep-like cortical activation under wake like motor

control. Sleep paralysis is the lack of motor control after awakening from REM sleep; this could be conceived as the continuation of REM sleep atonia during wake like cortical activation. Cataplexy, the focus of this thesis, is the sudden loss of postural muscle tone during wake, and is regularly conceptualized as entry into REM sleep atonia during wake like cortical activation.

\section{Section 1.5 - Cataplexy}

The focus of my research is primarily on the symptom of cataplexy. Cataplexy occurs during wake and is defined as a sudden loss of postural muscle tone, generally while maintaining consciousness. Cataplexy generally lasts from a few seconds to several minutes. 


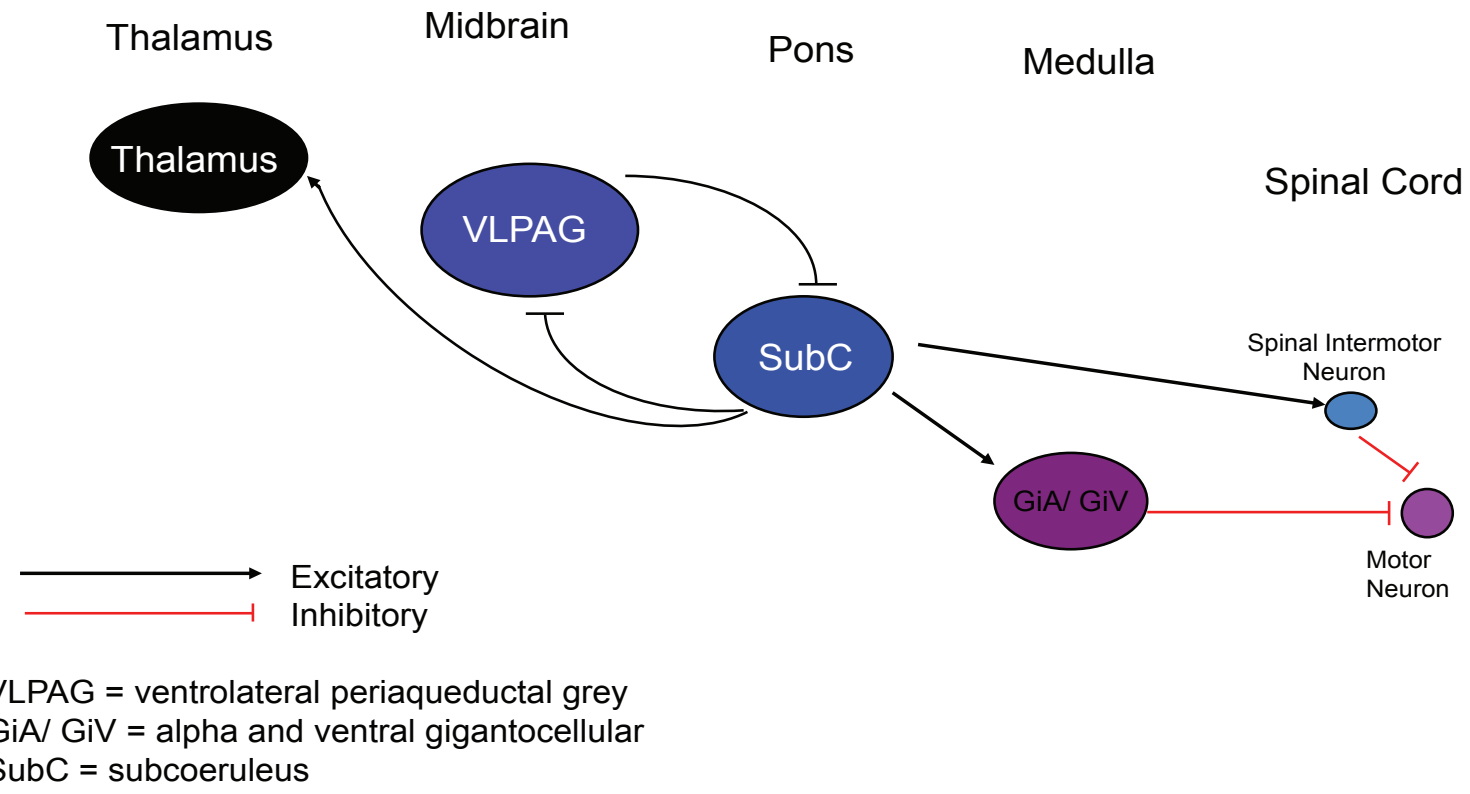

Table 1 - A schematic representing the the proposed circuitry underlying the role of the SubC in the cortical and motor atonia aspects of REM sleep 
Cataplexy is generally elicited by positive emotions, but can also be triggered by negative emotions or occur spontaneously. The current, but untested, conceptualization is that cataplexy is simply the intrusion of the REM sleep into waking $[4,5]$. The presence of REM sleep features such as interrupted breathing (apneas) and abolishment of the H-reflex during cataplexy support this view $[4,5]$.

Section 1.6 - Neurobiology of Cataplexy

Section 1.6.1- Gabaergic mechanisms in cataplexy

Work on the role of GABAergic mechanisms in regulation cataplexy has yielded mixed results. As described earlier, GABAergic neurons involved in REM sleep are often described as either REM-on or REM-off. Lesions of REM-off VLPAG neurons, which are believed to gate the onset of REM sleep, do not alter cataplexy levels in narcoleptic mice. However, the REMON GABAergic neurons of the ventral medial medulla (GiV) appear to play a role in cataplexy. Using unit recording in freely behaving narcoleptic dogs the REM-ON neurons, which correspond to the inhibitory premotor neurons of the GiV in rodents, were highly active during both REM sleep and cataplexy [35]. This provides some evidence in support of a shared mechanism between REM sleep and cataplexy. Yet to be studied is if the REM-ON glutamatergic and GABAergic neurons of the SubC are involved in cataplexy. My thesis will address this gap in the literature.

Section 1.6.2- Cholinergic mechanisms in cataplexy

One of the most well studied systems for cataplexy has been the cholinergic system. Cholinergic groups are REM-ON, and as expected exacerbate cataplexy. Pharmacological administration of cholinergic agonists have been shown to increase cataplexy in narcoleptic 
dogs and mice [36, 37]. Histological findings indicate increased cholinergic activity in canine and murine models of narcolepsy. There is an increase in the number of PPT/LDT neurons in narcoleptic dogs and increased choline acetyltransferase (ChAT) staining intensity in LDT neurons in narcoleptic mice [38, 39]. Taken together, this evidence suggests that the cholinergic system plays a pivotal role in the manifestation of cataplexy.

Section 1.6.3- Monoaminergic mechanisms in cataplexy

The monoaminergic groups are often conceptualized as REM-off, so we would expect their activity to be at a minimum during Cataplexy. The noradrenergic neurons of the LC have been shown to fire in a state-dependent manner, activity is highest during periods of active waking, and almost silent during REM sleep as well as cataplexy[40]. The LC is heavily innervated by hypocretin neurons of the lateral hypothalamus which provides a functional link to the disorder of narcolepsy [3]. Drugs which increase noradrenergic release, such as tricyclic antidepressants suppress cataplexy in humans, dogs and mice [41]. Surprisingly, prolonged optogenetic stimulation of the LC in mice caused behavioural arrests similar to cataplexy[42]. Dopamine is another monoamine which has been heavily implicated in the clinical treatment of narcolepsy and cataplexy. Amphetamines and modafinil are thought to increase wakefulness by increases dopamine levels and often used in treatment of narcolepsy and cataplexy [43, 44]. Findings from our lab indicate that D2 receptor agonist quinpirole suppresses cataplexy without altering sleep. A role for the serotonergic system in cataplexy has not been established. Firing of dorsal raphe is not suppressed to REM sleep levels during cataplexy [45]. With the exception of serotonin, it appears as through REM-off monoaminergic groups are critical to cataplexy. 
Section 1.7 - REM sleep and Cataplexy - Shared Mechanism?

There are a number of inconsistencies with the hypothesis that cataplexy share common neural mechanism with REM atonia. Although, during both REM sleep and cataplexy there is a cessation of firing of LC neurons, a number of neural groups lack this parallel. Histaminergic neurons do not change their firing during cataplexy, and DRN serotonin neurons show only a reduction and not a complete cessation of activity, as seen in REM sleep [46]. Lesions of REMoff VLPAG in narcoleptic mice caused less REM sleep without altering cataplexy [47]. Many of the drug treatments which suppress cataplexy have no effect on REM sleep [48]. Cataplexy is the sudden loss of muscle function which ranges from slight weakness such as inability to speak clearly, to a complete body collapse. Not all episodes are marked by full and complete atonia as marked by REM sleep [49]. REM sleep follows an ultradian rhythm, whereas cataplexy does not. Also REM sleep is regulated homeostatically, whereas cataplexy is triggered [43].

In fact, many physiological criteria of cataplexy differ from physiological changes characteristic to REM sleep, suggesting they may not share a common mechanism (Table 2) [50]. The literature has clearly elucidated a fundamental role for the SubC in REM sleep; however its functional importance to cataplexy remains speculative at best. Clearly elucidating the role REM circuitry plays in cataplexy is of paramount importance to both the scientific and medical understanding of narcolepsy.

\section{Section 1.8 - DREADDs Technology}

I inactivated the SubC using a novel pharmacosynthetic technique called DREADDs. DREADD stands for Designer Receptors exclusively activated by Designer Drugs. DREADDs were developed [51] by introducing a point mutations to muscarinic acetylcholine receptors. As a result of these mutations the receptors showed decreased sensitivity to acetylcholine, their native ligand, and increased sensitivity to a designer drug clozapine-N-oxide (CNO). CNO was 


\begin{tabular}{|c|c|c|}
\hline & CATAPLEXY & REM SLEEP \\
\hline Breathing Rate & $\begin{array}{l}\text { Irregular } \\
\text { \{Vetrugno, 2010\} }\end{array}$ & $\begin{array}{l}\text { Irregular } \\
\text { \{Snyder, 1964\} }\end{array}$ \\
\hline Blood Pressure & $\begin{array}{l}\text { No Changes } \\
\text { \{Vetrugno, 2010\} }\end{array}$ & $\begin{array}{l}\text { Increase } \\
\text { \{Snyder, 1964\} }\end{array}$ \\
\hline Heart Rate & $\begin{array}{l}\text { Lower } \\
\text { \{Vetrugno, 2010\} }\end{array}$ & $\begin{array}{l}\text { Increased (but } \\
\text { irregular) \{Snyder, 1964\} }\end{array}$ \\
\hline Consciousness & $\begin{array}{l}\text { Hypnagocic } \\
\text { Hallucinations }\end{array}$ & Dreaming \\
\hline $\begin{array}{l}\text { EEG } \\
\text { Characteristics }\end{array}$ & $\begin{array}{l}\text { Increased Theta } \\
\text { Rhythm } \\
\text { \{Bastianini, 2012\} }\end{array}$ & $\begin{array}{l}\text { Increased Theta } \\
\text { Rhythm } \\
\text { \{Bastianini, 2012\} }\end{array}$ \\
\hline Body Temperature & $?$ & $\begin{array}{l}\text { Decrease } \\
\text { \{Snyder, 1964\} }\end{array}$ \\
\hline Muscle Tone & $\begin{array}{l}\cdot \text { Rhythmic } \\
\text { suppression and } \\
\text { rebounds of EMG } \\
\text { activity } \\
\text { •\{Serra, 2008\} }\end{array}$ & $\begin{array}{l}\text { - Lack of postural } \\
\text { muscle tone } \\
\text {-Periodic muscle } \\
\text { twitches that } \\
\text { punctuate sleep } \\
\text { atonia }\{\text { Peever, } 2011\}\end{array}$ \\
\hline Triggered & $\begin{array}{l}\text {-Triggered by } \\
\text { Emotion }\end{array}$ & -No Trigger \\
\hline
\end{tabular}

Table 2 - Physiological criteria of cataplexy differ from physiological changes characteristic of REM sleep, suggesting they may not share a common mechanism 
used because of its relatively low affinity to any endogenous receptor, thus ensuring specific activation of only DREADDs receptors. The engineered DREADDs show the same G proteincoupling preference as their muscarinic receptor counterpart. The excitatory HM3D works along the $\mathrm{G}_{\mathrm{q}}$ coupled pathway common to M1, M3 and M5 muscarinic receptors; whereas the inhibitory HM4D works along the Gi/o pathway common between M2 and M4 muscarinic receptors. The physiological effects of mutant $\mathrm{G}$ protein-coupled receptor activation has been shown to be very similar to the wild-type counterpart [52].

The aim of my study is to determine if inhibition of the SubC leads to changes to REM sleep and cataplexy. Therefore I will use the HM4Di inhibitory DREADD to temporally and spatially inactive neurons of the SubC. The HM4Di inhibitory DREADD leads to neuronal -rectifying potassium

(GIRK) channels. Activation and opening of the GIRK channels to causes the neuron to become more permeable to potassium ions, resulting in hyperpolarization of the cell.

\section{Section 1.8.1 - Properties of Clozapine-n-Oxide}

CNO is a relatively inert ligand which has been shown to be inert in the absence of DREADDs expression. In rodents there is no detectable back-transformation of CNO to clozapine [53]. Taken together CNO appears to specifically target DREADDs expressing cells. Pharmacokinetic studies indicate that a $1 \mathrm{mg} / \mathrm{kg}$ dose of CNO in mice lead to a peak in plasma CNO levels at 15 minutes post injection with levels of plasma CNO were very low 2 hours post injection [54]. Despite this relatively short plasma half-life of CNO in mice, in-vivo studies have shown biological effects of acute CNO treatment much longer than 2 hours, in the range of 6-10 hours. Dosages of the CNO administrated has been variable in the literature with anywhere from 
0.001 to $10 \mathrm{mg} / \mathrm{kg}$ used. The use of DREADDs mediated inhibition of brainstem neurons has been confirmed in the literature already, generally using of 10mg/kg doses of CNO [55-57]. 


\section{Section 2 - AIMS}

My thesis will use novel pharmacosynthetic interventions to shed light on the role REM circuits play in cataplexy. In doing so I will test the current understanding of the role the SubC plays in maintaining motor atonia. Furthermore, I will provide the quantitative muscle tone analysis lacking in existing SubC studies [12]. A knockout mouse which does not express the hypocretin ligand was developed, and it displayed sleep dysregulation which is similar to both human and canine narcolepsy. Hypocretin knockout mice experience cataplexy and sleep excessively during their active phase [5, 6]. I will use this rodent model of narcolepsy for all of my investigations. My study will provide a quantitative investigation of the role the SubC plays in REM sleep atonia. Currently our understanding is limited to only qualitative reports of muscle activity change, quantification of changes to muscle tone due to SubC lesions have not been reported in mice or rats.

The goal of my MSc thesis is to provide greater understanding of the neurological mechanisms which control REM sleep and if these mechanisms underlie cataplexy. I am doing this by examining the brainstem neural circuits that regulate both natural and pathological (i.e., narcolepsy/cataplexy) aspects of REM sleep in mice.

AIM 1 - Determine if SUBC inhibition leads to alterations of sleep wake architecture.

Hypothesis: We would expect to observe less REM sleep, and if REM sleep and Cataplexy share circuitry (act through the SUBC), we should also expect less Cataplexy.

AIM 2 - Determine if SUBC inhibition leads to alterations in normal motor tone profile. 
Hypothesis: We would expect a loss of REM sleep atonia, and if REM sleep and Cataplexy share circuitry (act through the SUBC), we should also expect heightened motor tone during in the cataplectic attacks which do occur. 


\section{$\underline{\text { Section } 3 \text { - Methods }}$}

Section 3.1 $\underline{\text { Animals }}$

Experiments used male, hypocretin KO mice on a C57BL/6 background and male wild-

CCGCTATCAGGACATAGCGTTGGC. All procedures and experimental protocols were approved by the University of Toronto’s animal care committee and were in accordance with the Canadian Council on Animal Care.

\section{Section 3.2 Viral Transduction}

A viral vector was used to introduce an engineered M4 muscarinic receptor AAV-hSynHA-hM4D(Gi)-IRES-mCitrine (serotype 5) (Figure 2). This virus was constructed by Dr. Bryan Roth at the University of North Carolina - Chapel Hill, and was purchased from the UNC vector core This virus was a non-specific and transduced in all neurons with the hSyn promoter. Associated with the DREADDs receptor was the fluorescent probe mCitrine to allow for localization of viral expression. mCitrine is a yellow-green monomeric flurorescent protein which is a variant of green fluorescent protein (GFP). mCitrine has optimal excitation and emission wavelengths of 516nm and 529nm respectively. As mentioned earlier, these engineered receptors remained dormant until a specific designer drug (CNO) was administered. In the presence of CNO a G-coupled protein response altering membrane permeability leading to hyperpolarization and thus silencing of the targeted neurons. After turning off neurons of the SubC, I studied their role in regulating the muscle tone, twitch activity, cortical activity and overall sleep-wake architecture in hypocretin knockout mice. An advantage to this technique is 


\section{A) Inhibitory DREADD (AAV5)}

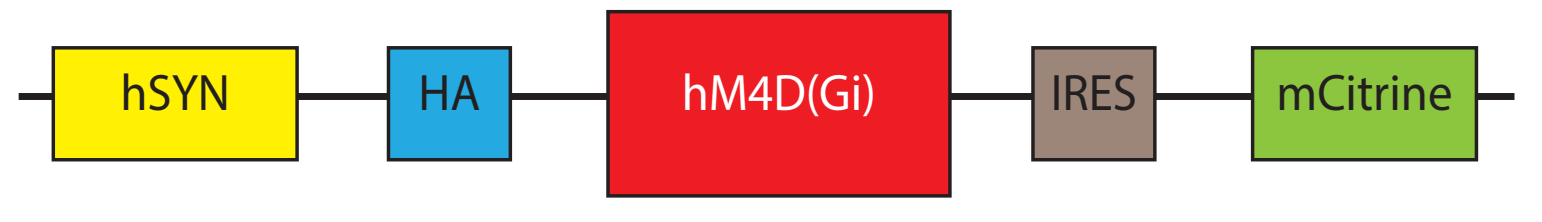

B) Control Vector (AAV5)

\begin{tabular}{|l|l|l}
\hline hSYN & EGFP \\
\cline { 3 - 3 } & &
\end{tabular}

Figure 2 - Schematic of adeno associated vectors. A) Design of hM4Di-mCitrine. AAV-hSyn-HA-hM4D(Gi)-IRES-mCitrine) B) Design of EGFP vector control (AAV-hSyn-EGFP). hSYN, human Synapsin I promoter; HA, hemagglutinin; IRES, internal ribosome entry site; EGFP, enhanced green fluorescent protein. 
that the silencing is reversible; once the CNO has been metabolized the target area is freed from inhibition. This leads to a considerable advantage to this study, our manipulation will lead to temporally and spatially controlled inactivation of the SubC.

\section{Section 3.3 $\underline{\text { Surgery/ Experimental Protocol }}$}

Experimental procedures used were adapted from existing protocols from our lab [58]. On Day 1, mice underwent sterile surgery for injection of AAV. Isoflurane anesthetic (0.5\% to 2\%) (Baxter, Mississauga, ON) was introduced to oxygen gas using an isoflurane vaporizer (T3IS0, Benson Medical Industries, Markham, ON). Gas flow was regulated via a variable flow-meter system (Western Medica, West Lake, $\mathrm{OH}$ ) to a flow rate of 100-400 mL/min. Outflow of gas from the induction chamber was vented into an activated-carbon scavenging canister (A.M. Bickford INC, Wales Center, NY). A heating pad (TC-1000; CWE, INC, Andromore, PA) was used to maintain a body temperature of $37-38^{\circ} \mathrm{C}$.

The animal was secured with ear bars and a snout clamp (David Kopf Instruments, Chatsworth, CA). A midline incision from the frontal bone to the caudal base of the skull was made. After leveling of the head, approximately 400nL of adeno-associated viral (AAV) vector (serotype 5) containing hSyn-HA-hM4D(Gi/o)-IRES-mCitrine was injected using a 26g stainless steel cannula attached to a 10ul Hamilton syringe driven by a syringe driver (Harvard Apparatus). AAV injections were targeted to the SubC using the following coordinates: AP= 5.0mm, ML $= \pm 0.9 \mathrm{~mm}, \mathrm{DV}=-4.2 \mathrm{~mm}$ in hypocretin knockout mice ( $\mathrm{n}=7 ; 28$-32gm). Mice were allowed to recover from injection for 2 weeks. On Day 14, mice underwent sterile surgery for implantation of electroencephalogram (EEG) electrodes and electromyogram (EMG) electrodes into the neck. EEG's were obtained using four stainless steel micro-screws. The screws were placed at $1 \mathrm{~mm}$ anterior $\pm 1.5 \mathrm{~mm}$ lateral to bregma and $3 \mathrm{~mm}$ posterior $\pm 1.5 \mathrm{~mm}$ lateral to bregma. EMG electrodes were made from multistranded stainless steel (AS631 Cooner Wire, 
Chatsworth, CA) wires, which were sutured onto the surface of the neck and masseter muscles. All electrodes were attached to a micro-strip connector (CLP-105-02-L-D, Electrosonic, Toronto, ON) which was affixed to the skull with dental cement (Ketac-cem, 3M, London, ON). After surgery the mice were given ketoprofen $(3 \mathrm{mg} / \mathrm{kg})$ for pain management. Animals were housed in clean, rectangular polysulphone cages lined with corncob chip bedding with environmental conditions maintained at $20{ }^{\circ} \mathrm{C}$ and $60 \%$ humidity, with a 12 hour light -12 hour dark cycle (lights on 7:00, lights off 19:00). Animals had ad libitum access to drinking water and rat chow (Lab Diet, PMI Nutrition International, St. Louis, MO). Animals were then given 14 days to recover.

\section{Section 3.4 Drugs and Administration}

Clozapine N-oxide (CNO; C0832, Sigma-Aldrich, Oakville,ON) was dissolved in saline to a concentration of $0.5 \mathrm{mg} / \mathrm{ml}$ with $0.05 \%$ DMSO in saline. $600 \mathrm{ul}$ of CNO was administered by intraperitoneal injection into each mouse for a dosage of $10 \mathrm{mg} / \mathrm{kg}$ at $6: 30 \mathrm{pm}$. Vehicle control injections were conducted using saline with $0.05 \%$ DMSO in saline. 600ul of $0.05 \%$ DMSO in saline solution was administered by intraperitoneal injection into each mouse 6:30pm From our initial findings sleep-wake architecture appeared to be altered for the first thirty minutes post saline and CNO injection (. These changes could be due to a stress response to handling. For this reason injections of preceded the onset of the dark phase, the period in which cataplexy is most often seen, to ensure this stress response did not carry over.

\section{Section 3.5 Data Acquisition}

Sleep-wake state and muscle activity were recorded by attaching a cable to the headplug

fixed to the mouse's head. The cable was connected to a Super-Z High Impedance Head Stage for neck EMG and EEG signals $1000 \mathrm{~Hz}$. Signals were further amplified using a and a BMA-400 
AC/DC Bioamplifier (CWE Inc., Ardmore, PA). The EEG was amplified 200 times and band-pass filtered between 1 and $100 \mathrm{~Hz}$. EMG signals were amplified 200 times and band-pass filtered between $30 \mathrm{~Hz}$ and $1 \mathrm{kHz}$. All electrophysiological signals were digitized at $500 \mathrm{~Hz}$ (Spike 2 Software, 1401 Interface, CED Inc.), and synchronized with video recordings (1080p Lifecam HD, Microsoft, Seattle,WA). These recordings were stored on the computer for later analysis.

\section{Section 3.6 Bilateral SubC HM4Di Injections}

To determine the effect of inhibiting REM circuitry on the appearance of cataplexy and sleep-wake architecture, mice (n=7) were injected with 400nl AAV-hSyn-HA-hM4D(Gi)-IRESmCitrine bilaterally into the SubC $(\mathrm{AP}=-5.0 \mathrm{~mm}, \mathrm{ML}= \pm 0.9 \mathrm{~mm}, \mathrm{DV}=-4.2 \mathrm{~mm})$. Mice were given 2 weeks to recover before implantation with EEG and nuchal EMG. After an additional 2 weeks, mice were connected to a recording tether and given three days to habituate. During habituation mice were handled to daily at 6:30pm. Post habituation, three days of baseline recording were taken. Days 4 - 9 consisted of three days of CNO $(10 \mathrm{mg} / \mathrm{kg})$ or three days vehicle control (saline with 0.05\% DMSO) injections at 6:30pm intraperitoneally. Treatment was randomized with some animals receiving saline first, and others receiving CNO first.

\section{Section 3.7 Bilateral SubC Viral Control Injections}

To control for the effect of viral incorporation of genetic information into the region on the SubC, hypocretin KO mice $(n=3)$ were injected with 400nl AAV-hSyn-EGFP bilaterally into the SubC $(\mathrm{AP}=-5.0 \mathrm{~mm}, \mathrm{ML}= \pm 0.9 \mathrm{~mm}, \mathrm{DV}=-4.2 \mathrm{~mm})$. Mice were given 2 weeks to recover before implantation with EEG and nuchal EMG. Behavioral experiments were conducted as mentioned above (Bilateral SubC HM4Di Injections) 
Section 3.8 Histological Confirmation of viral targeting to the SubC

Upon completion of drug administration mice were sacrificed via transcardial perfusion, using PBS followed by 4\% PFA, brain tissue was harvested then post-fixed for 24 hours followed by preservation in 30\% sucrose in PBS. Brains were sliced at $40 \mathrm{uM}$, and slices from midbrain to spinal cord were collected. For experimental mice injected with 400nL of AAVhSyn-HA-hM4D(Gi)-IRES-mCitrine, immunohistological amplification of the mCitrine fluorescent protein was conducted. Primary rabbit anti-GFP antibody was used with secondary CY3 Goat anti-rabbit antibodies. Slides were initially visualized under an fluorescent microscope (BX50W1 Olympus Microscope, Carsen Group Inc., Markham, ON). Slides were imaged using an Olympus slide scanner (FSX100, Olympus, Center Valley, PA) under 570 nm light and analysed using cellSens (Version 1.5 Olympus, Center Valley, PA). For AAV control mice injected with 400nL of AAV-EGFP, the EGFP fluorescent protein was imaged using Olympus slide scanner (FSX100, Olympus, Center Valley, PA) under $480 \mathrm{~nm}$ light and analysed using cellSens (Version 1.5 Olympus, Center Valley, PA).

\section{Section 3.9 Data Analysis}

Cortical EEG, EMG activity and videography were compiled in Spike2 software (CED, Cambridge, UK), and were used to determine motor activity and sleep-wake state. Recordings were segmented in 5 second epochs which were scored for active wake, quiet wake, non-rapid eye movement sleep (NREM), rapid eye movement sleep(REM), cataplexy and sleep attacks. Active wake was characterised by high-frequency, low-voltage EMG with high EMG tone (with overt and directed motor activity). Quiet wake was characterized by high-frequency, lowvoltage EEG activity and moderate EMG tone (but no overt motor activity); NREM sleep was distinguished by high-amplitude, low-frequency EEG signals and minimal EMG tone. 
Cataplexy was scored as sudden and abrupt loss of muscle tone during wakefulness, along with low voltage, high frequency EEG. Cataplexy was scored only when it lasted at least 10 seconds, and was preceded by at least 40 seconds of wake. Lastly, sleep attacks were classified as a gradual loss of skeletal muscle tone from waking levels, and associated with NREM-like EEG characteristics (high-amplitude, low-frequency EEG signals).

\section{Section 3.10 REM and Cataplexy episode EMG analysis}

One of the main aims of my thesis was to determine if the sudden loss of muscle tone observed in cataplexy is due to improper activation of REM sleep atonia mechanisms. First, we wanted determine if SubC inhibition lead to motor changes not specific to REM sleep. Overall muscle activity in each vigilance state (active wake, quiet wake and NREM) was determined. Overall neck muscle activity was analyzed under saline and CNO, and normalized to back to baseline values for each vigilance state in each mouse.

To determine if REM sleep specific alterations occurred after SubC inhibition a more refined analysis was needed. REM sleep motor profile is characterized as overall muscle atonia punctuated by brief phasic events or twitches. It is hypothesized that these two phenomena of REM sleep motor control are mediated by different mechanisms; therefore an analysis which would distinguish each tonic from phasic activity was needed. To quantify phasic and tonic muscle activity I used a muscle analysis algorithm developed by Dr. Patricia Brooks. This algorithm distinguishes and quantifies the phasic (i.e., muscle twitches) and tonic (atonia) periods of REM sleep [59]. To do this, all episodes were identified and the nuchal EMG activity in each episode was quantified in 10ms epochs using Spike2 software (CED, Cambridge, UK). To differentiate between tonic and phasic periods of EMG activity, the first 5 seconds of the episode in which no phasic muscle twitches occurred was identified. After identifying a 5s 
period of non-phasic activity, the 99th percentile of EMG activity occurring during this 5s was determined. Since EMG activity was quantified in 10ms epochs, this meant ranking the values of EMG activity that occurred in all 500 epochs (ie. 10ms epochs over 5s) and determining the value at which $99 \%$ of these 500 values fell below. This calculated value was then used as the threshold to separate tonic and phasic activity. The muscle twitches that define phasic REM sleep were classified as motor events that exceeded this threshold value (ie. exceeded the 99th percentile); conversely, tonic activity (ie. REM atonia) was classified as any period in which muscle activity was equal to or less than the threshold value (ie. less than the $99^{\text {th }}$ percentile). The threshold value was calculated for each REM sleep and cataplexy episode and atonia and muscle twitches were quantified for each REM and cataplexy episode during baseline and for each pharmacological manipulation performed. All muscle activity analysis was done on animals with artifact free nuchal EMG signals.

To determine if the motor manifestation of cataplexy was altered by SubC inhibition, muscle activity was analyzed prior to, during and after cataplexy was determined in saline and CNO groups. Prior to values represent the muscle activity for first full 5 second epoch of active wake which precedes cataplexy onset; this value was used as the standard to normalize \% drop. Cataplexy muscle activity was determined as the first full 5 second epoch of cataplexy in each episode. The after cataplexy value represents the first full 5 second epoch of active wake following cataplexy attack.

\section{Section 3.11 - $\underline{\text { REM and Cataplexy episode EEG spectral analysis }}$}

EEG spectral analysis was calculated using fast Fourier transformation of each REM sleep episode, yielding a power spectra profile within five frequency bands $(n=4)$ using Spike2 software (CED, Cambridge, UK). 
66.12 Hz. To account for variability in absolute power between individuals; EEG power in each frequency bin was expressed as a percentage of the total EEG power in the epoch. The spectral profiles of was then compared between saline and CNO treatments.

\section{Section 3.12 - Statistical Analysis}

The specific statistical tests used for each experiment are stated within the results section. Bonferroni’s post-test analysis was used to determine statistical significance whenever two-way ANOVAs were performed. All statistical analyses were performed electronically using Prism5 (GraphPad, La Jolla, CA). Data are presented as a mean \pm standard error of the mean. 


\section{Section 4 - Results}

Section 4.1 - Viral transgenes were targeted to the SubC region

SubC neurons were targeted by stereotaxically injecting an adeno-associated virus into hypocretin knockout mice ( $n=7)$. I validated the specificity and efficiency of transgene expression by visually comparing viral mCitrine expression amplified with anti-GFP immunohistochemistry. GFP fluorescence was primarily detected at the ponto-medullary junction in the area which corresponds to the SubC, with sparing expression in neighboring regions (Figure 4). The AAV-hSyn-EGFP control mice $(n=3)$ were also targeted to the pontomedullary junction in the area which corresponds to the SubC (Figure 3).

Section 4.2 - $\underline{\text { CNO without HM4Di does not alter sleep-wake architecture. }}$

To control for possible effects of CNO on sleep wake architecture a group of mice $(n=3)$ were virally transduced with EGFP lacking the HM4di protein. These EGFP control mice were injected with $10 \mathrm{mg} / \mathrm{kg}$ of CNO and sleep wake architecture was observed. Over the first three hours post CNO injection, no changes were observed in any state (active wake, quiet wake, NREM, REM, cataplexy and sleep attacks) compared to baseline or saline groups (Figure 5). This confirmed that my dose of $10 \mathrm{mg} / \mathrm{kg}$ of CNO, did not lead to non-specific sleep-wake architecture changes.

Section 4.3 - Changes to sleep-wake architecture were not due to handling or intraperitoneal (I.P) injection

During the first three hours post injection, there were no alterations in any vigilance state due to injection of saline vs. baseline recordings (Figure 6). Time spent in active wake, quiet 

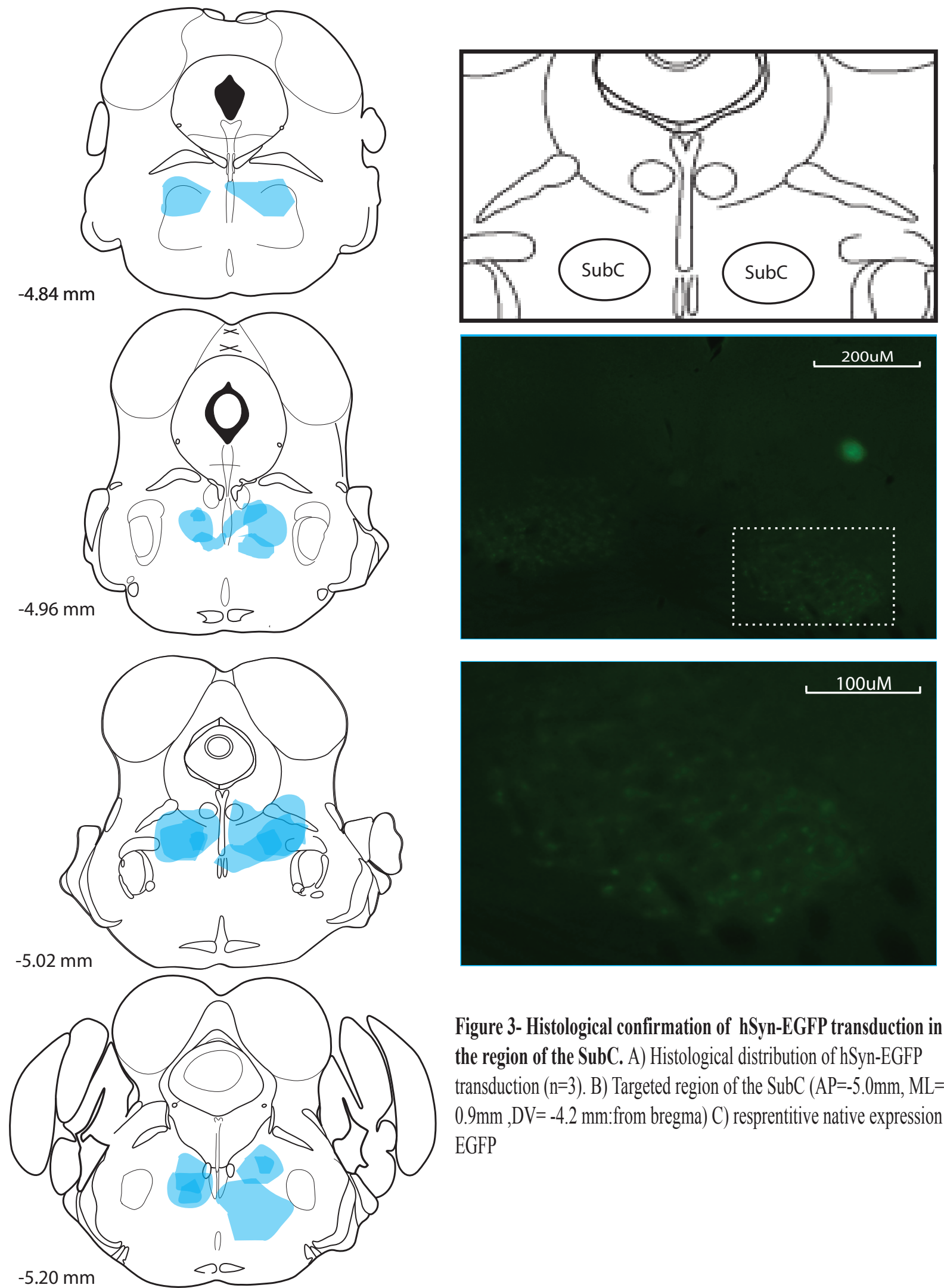

Figure 3- Histological confirmation of hSyn-EGFP transduction in the region of the SubC. A) Histological distribution of hSyn-EGFP transduction $(\mathrm{n}=3)$. B) Targeted region of the $\mathrm{SubC}(\mathrm{AP}=-5.0 \mathrm{~mm}, \mathrm{ML}= \pm$ $0.9 \mathrm{~mm}, \mathrm{DV}=-4.2 \mathrm{~mm}$ :from bregma) C) resprentitive native expression of EGFP 

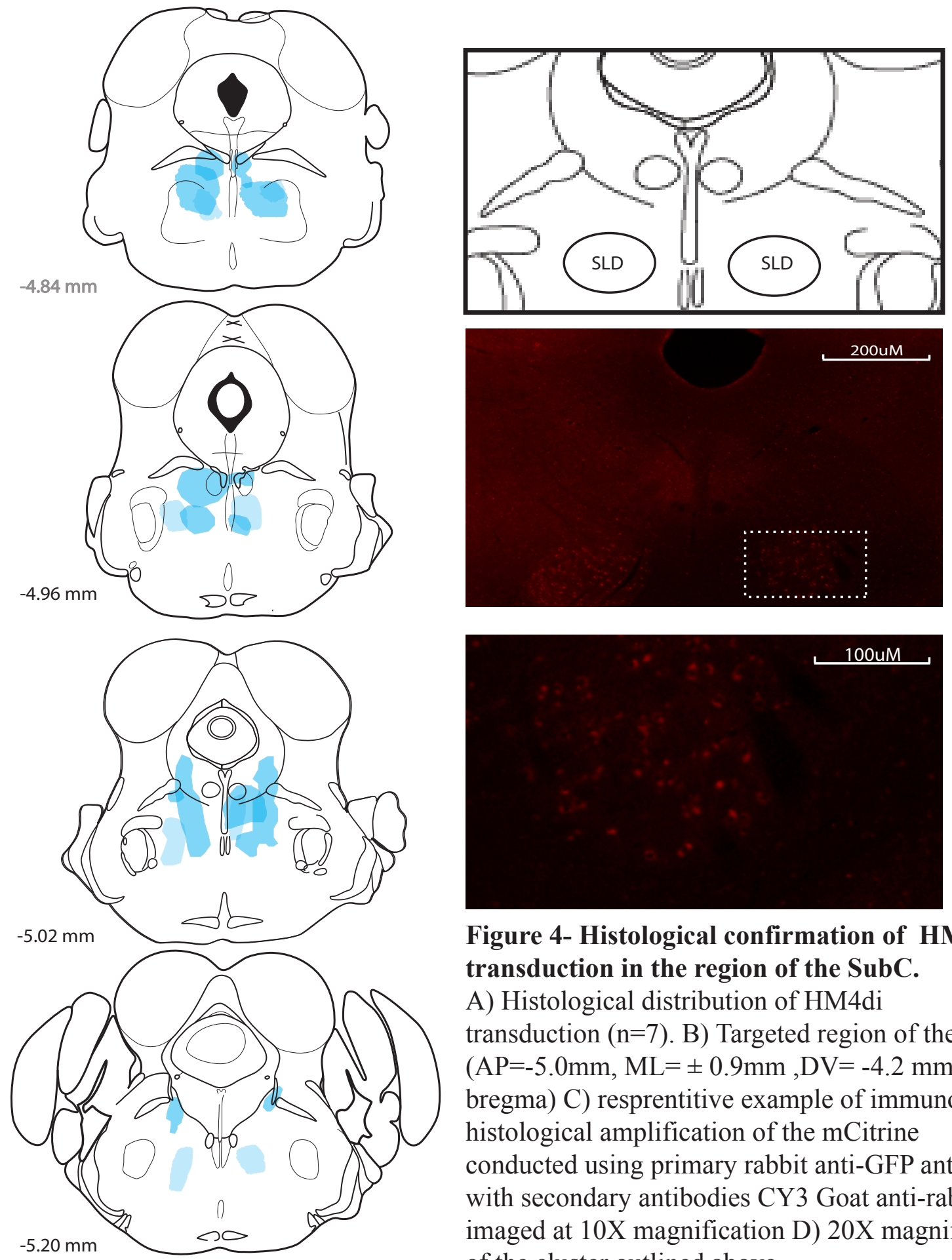

Figure 4- Histological confirmation of HM4di transduction in the region of the SubC.

A) Histological distribution of HM4di transduction $(\mathrm{n}=7)$. B) Targeted region of the SubC $(\mathrm{AP}=-5.0 \mathrm{~mm}, \mathrm{ML}= \pm 0.9 \mathrm{~mm}, \mathrm{DV}=-4.2 \mathrm{~mm}$ :from bregma) C) resprentitive example of immunohistological amplification of the mCitrine conducted using primary rabbit anti-GFP antibody with secondary antibodies CY3 Goat anti-rabbit. imaged at 10X magnification D) 20X magnification of the cluster outlined above 


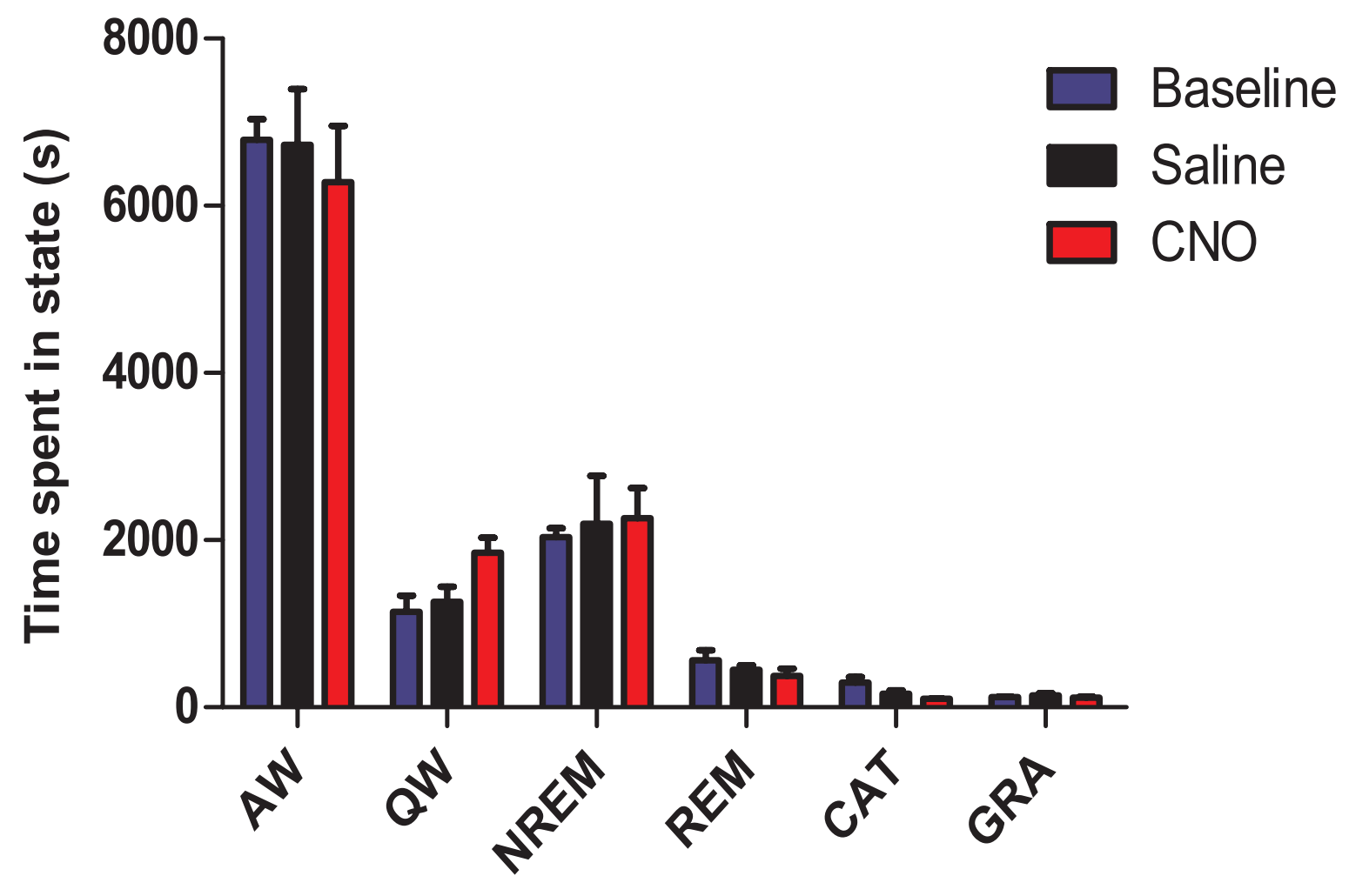

Figure 5 - CNO (10mg/kg) does not alter sleep-wake architecture in animals lacking viral HM4di incorporation. Mice $(n=3)$ with stereotaxic injection of AAV-hSyn-EGFP in the SubC show no alteration in wake, sleep, or narcoleptic attacks (CAT=cataplexy; GRA=gradual arrest). 
wake, NREM, REM, cataplexy and sleep attacks did not change after saline (with 0.05\%

DMSO) injection compared to baseline (Table 3) (2way ANOVA; bonferroni post-test p <0.05).

Hypnograms of the first hour post injection indicate that there is no observable change to sleep

wake transitions after handling and saline injection compared to baseline. This indicates that

handling or the act of intraperitoneal (I.P) injection does not alter sleep-wake architecture.

Therefore saline (with DMSO 0.05\%) group is a bonafide control, any effect observed between saline and CNO groups are due to SubC inhibition.

Section 4.4 - Inhibiting the SubC leads to changes to sleep-wake architecture up to two and a half hours post CNO injection.

To determine the duration for which CNO is effective in altering sleep-wake architecture, a time-course analysis was conducted. Time spent in vigilance states was broken down into 30 minute bins over the first three hours post injection. No changes to sleep wake architecture were observed during the first thirty minutes post injection. Many factors such as stress of injection and pharmacokinetics of CNO delivery may have led to the lack of effect in the 0-30 minute bin (Figure 7). For this reason data acquired from 0-30 minutes post injection were not included in subsequent analyses.

Significant changes to time spent in REM sleep were first observed in the second half of the first hour post injection. CNO administration began to alter REM sleep architecture at 19:00h. During the 30-60 minute period SubC inactivation lead to a significant 392\% increase in time spent in REM sleep. During the 60-90 minute this significant alteration continued with a 285\% increase in time spent in REM sleep. Significant increases to REM sleep were observed until 21:00 h. For this reason the recording period used in our analysis is from 19:00h to 21:00h. Alterations began to subside during the second half of the third hour. For this reason, the 


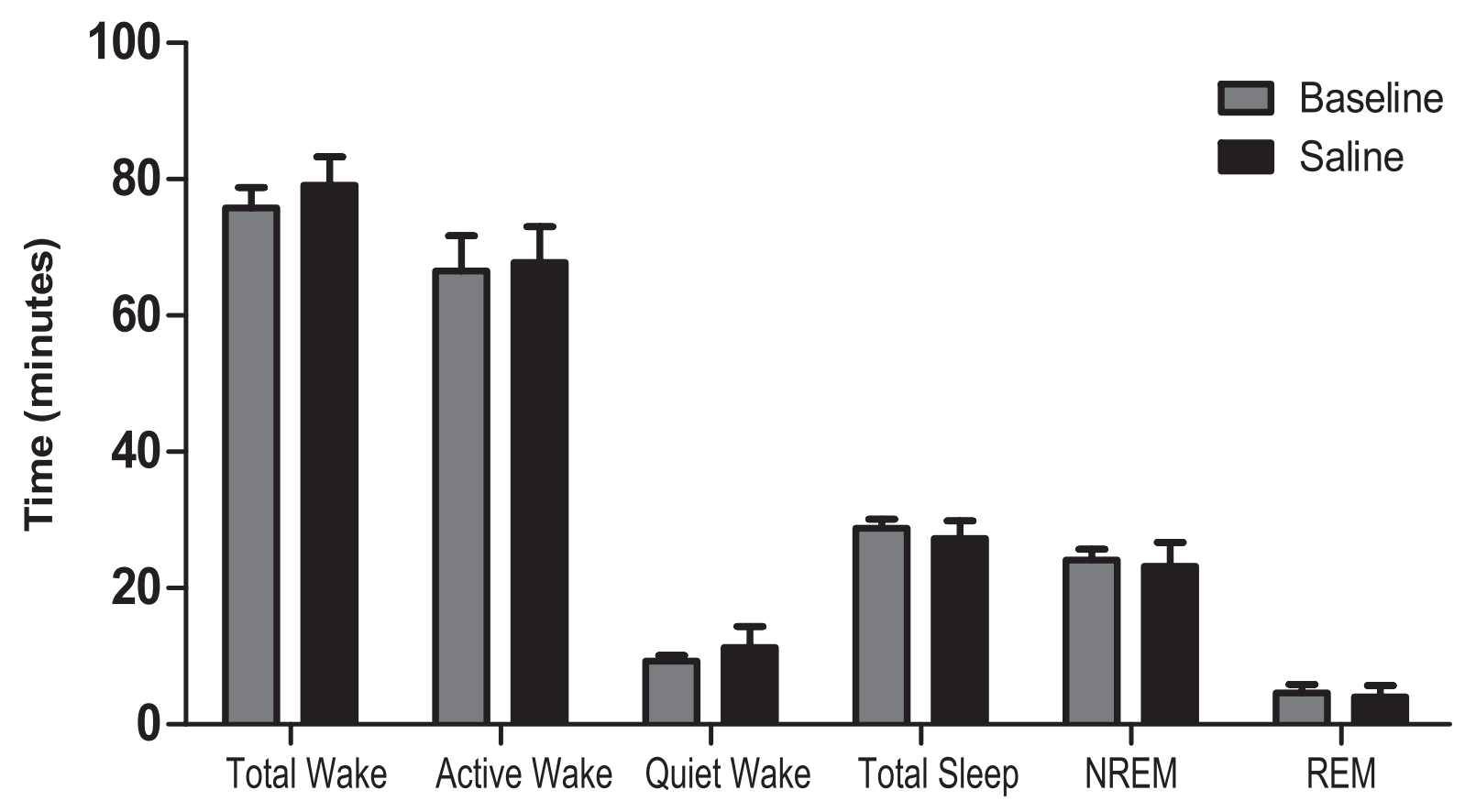

Figure 6- Intraperitoneal injection of saline does not effect sleep wake architecture compaired to baseline. There is no significant difference in time spent (minutes) in any sleep wake state during the first two hours of the dark phase (19:00-21:00h). 


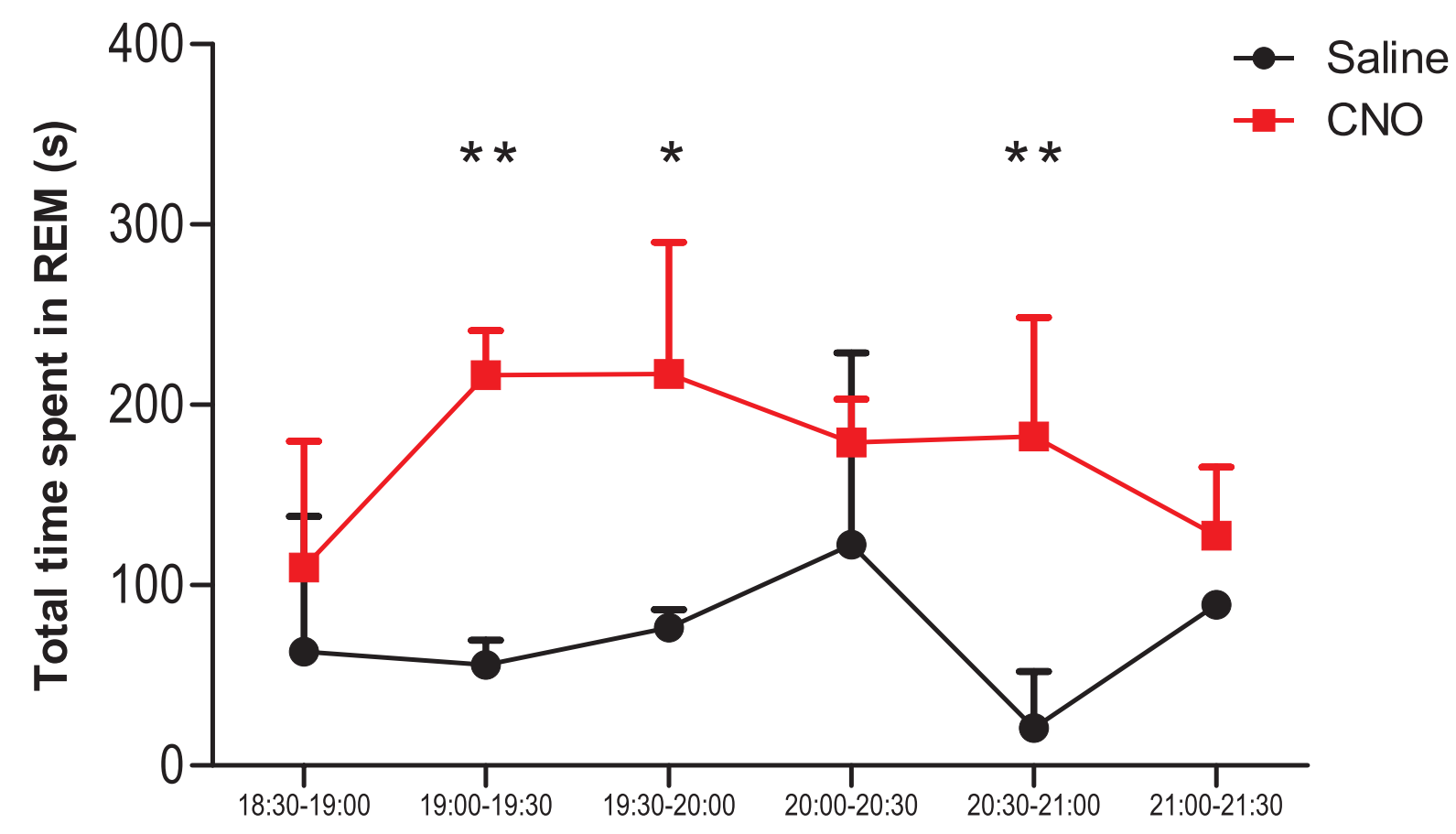

Figure 7 - The effect of CNO $(10 \mathrm{mg} / \mathrm{kg})$ injection on REM sleep architecture over the first three hours post-injection. CNO has a significant effect from 19:00h to 20:00h as well as from 20:30h to 21:00h, (2 way ANOVA bonferroni post test $\left.{ }^{*} \mathrm{p}<0.01,{ }^{* *} \mathrm{p}, 0.001\right)$. (saline: $\mathrm{n}=4 ; \mathrm{CNO} 10 \mathrm{mg} / \mathrm{kg}: \mathrm{n}=7$ ) 


\begin{tabular}{|c|c|c|c|c|c|c|}
\hline & \multicolumn{2}{|c|}{ Baseline $(n=5)$} & \multicolumn{2}{|c|}{ Saline $(n=4)$} & \multicolumn{2}{|c|}{$\mathrm{CNO}(\mathrm{n}=7)$} \\
\hline & Time (min) & SEM & Time (min) & SEM & Time (min) & SEM \\
\hline Total Wake & 75.75 & 3.07 & 79.15 & 4.11 & 63.38 & 1.83 \\
\hline Active Wake & 66.50 & 5.24 & 67.82 & 5.20 & 52.35 & 1.70 \\
\hline Quiet Wake & 9.26 & 0.90 & 11.33 & 3.02 & 11.03 & 1.95 \\
\hline Total Sleep & 28.80 & 1.35 & 27.29 & 2.57 & 43.52 & 2.73 \\
\hline NREM & 24.14 & 1.53 & 23.24 & 3.46 & 33.29 & 4.26 \\
\hline REM & 4.66 & 1.18 & 4.06 & 1.68 & 10.23 & 1.19 \\
\hline Cataplexy & 1.95 & 1.40 & 5.54 & 3.18 & 0.69 & 0.35 \\
\hline Sleep Attacks & 1.72 & 0.85 & 1.38 & 0.82 & 1.76 & 0.89 \\
\hline
\end{tabular}

Table 3 - Sleep wake architecture under baseline, saline injection, and CNO

$(10 \mathrm{mg} / \mathbf{k g})$ injection. Values represent the number of minutes spent in each state over the first two hours of the dark phase (19:00 - 21:00 h). 
efficacy of CNO inhibition of the SubC was optimal for the 2 hours between 19:00 to 21:00h (Figure 7).

Section 4.5 - Inhibiting the SubC leads to an increase in REM sleep.

It was found that neuronal silencing of the SUBC region using HM4Di DREADD led to alterations in the sleep wake architecture of hypocretin knockout mice, with the most profound effects to REM sleep (Figure 8). Inactivation of the SubC lead to a significant $19.9 \%$ drop in the time spent in wakefulness (1way ANOVA P=0.002). Upon re-examination, SubC inactivation had its effect on active wakefulness, leading to a significant $22.8 \%$ decrease in time spent in active wake. There was only a minimal 2.6\% decrease in time spent in quiet wakefulness. As a result of the decrease in time spent in wake, there was a significant $59.4 \%$ increase in time spent in sleep (1way ANOVA p=0.005). This increase in time spent in sleep manifested as a 152\% increase REM sleep (1way ANOVA P=0.006). An insignificant 43.3\% increase in time spent in NREM was also observed. In summary, inhibition of the SubC region led to increased somnolence. Time spent in active wakefulness, primarily spent grooming, eating and in locomotion dramatically decreased.

HM4di activation led to increases in REM sleep (Figure 9). Neuronal silencing of the SubC significantly increased the total amount of time spent in REM sleep. However the $46 \%$ increase in REM sleep episode duration and the 32\% increase in number of was not significant ( $\mathrm{P}=0.52$ and $\mathrm{P}=0.59$ respectively). Inhibition of the SubC lead to increases in REM sleep, however it is inconclusive if the increase was due to altering REM sleep triggering or REM sleep maintaining mechanism. 


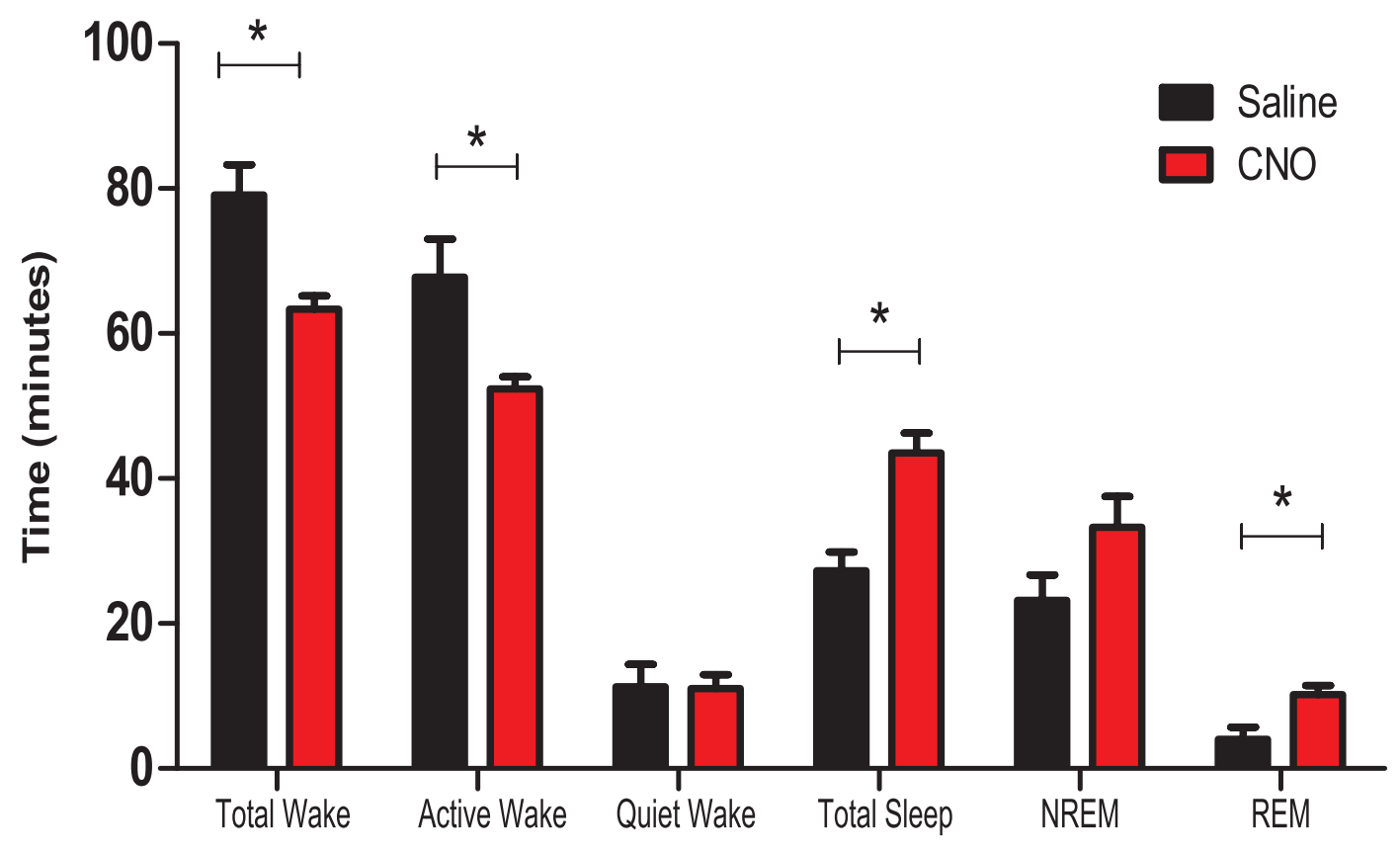

Figure 8 - Inhibition of the SubC leads to alterations of sleep-wake architecture over the first two hours of the dark phase (19:00-21:00h). There is a significant decrease in time spent in total wake $(* 1$ way ANOVA, $\mathrm{P}=0.002)$, with the majority of the decrease seen during the active wake (*1way ANOVA, $\mathrm{p}=0.006)$. The decrease in wake is accompanied with a significant increase in total sleep $(* 1$ way ANOVA, $p=0.005)$, with the majority of the increase seen during REM sleep (*1way ANOVA, $\mathrm{P}=0.006$ ). 

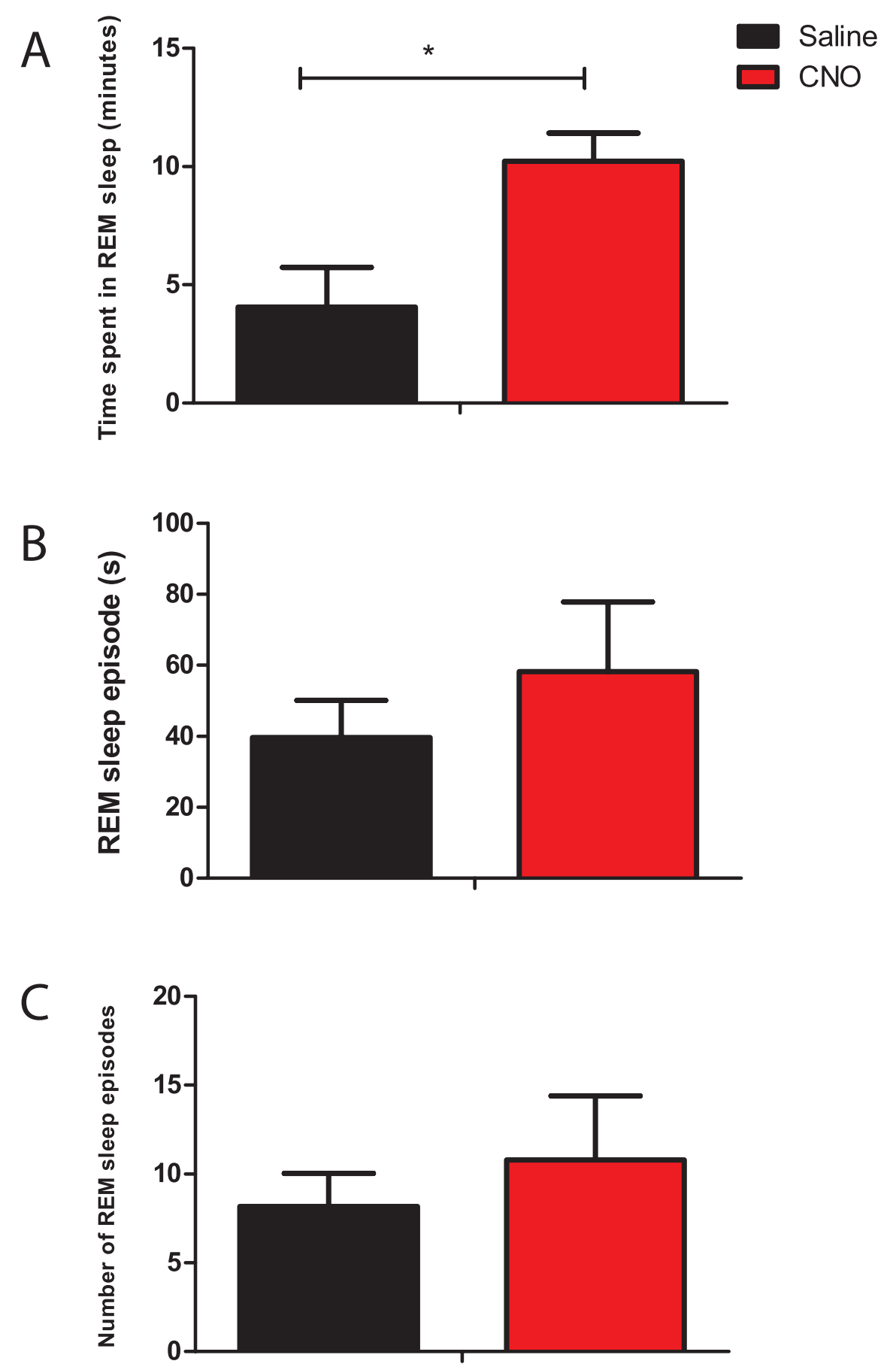

Figure 9 - SubC inhibition leads to increases the propensity towards REM sleep.

A) Significant increases to time spent in REM sleep during was observed under $\mathrm{CNO}(10 \mathrm{mg} / \mathrm{kg})$ injection (*t-test $\mathrm{p}=0.015)$. B) Significant changes were not observed for number and duration of REM sleep episodes. These values are representitive of the first two hours of the dark phase (19:00- 21:00h) 
Section 4.6 - Inhibiting the SubC increases fragmentation of sleep-wake cycle

Transitions between sleep and wake states were also altered under SubC silencing (figure 10). The number of transitions from NREM sleep to REM sleep increased after SubC inhibition. Under SubC inhibition there was a 5.7\% increase in the number of NREM to REM sleep transitions (t-test, $\mathrm{P}=0.028)$. The increased proportion of transitions into REM sleep from NREM sleep was offset by a $10.37 \%$ decrease in transitions from NREM sleep to wakefulness (t-test, $\mathrm{P}=0.031$ ). Transitions into and out of all other states did not vary during SubC silencing. These findings indicate that SubC inhibition makes entry to REM sleep a more conducive during NREM sleep.

Section 4.7 - Inhibiting the SubC led to a decrease in Cataplexy

A major focus of this study was to determine the mechanisms which underlie cataplexy and REM sleep are shared. Since profound alterations to REM sleep were observed, we expected alterations to cataplexy to follow suit. $14.3 \%$ of mice (1/7) did not present with cataplexy and was thus were not included in analysis. During the two hours post injection period there was a significant $87.7 \%$ decrease in time spent in cataplexy(t-test $\mathrm{p}=0.04)$. This decrease was primarily a result of 75\% fewer cataplexy episodes rather than duration of cataplexy episode (Figure 11). Under saline injection there was an average of $3.31 \pm 0.93$ cataplexy episodes per hour, this value dramatically dropped to $0.83 \pm 0.45$ cataplexy episodes under SubC inhibition (t-test: $\mathrm{p}=0.025)$. Durations of cataplexy episodes however were not significantly different from bouts under saline average. Cataplexy episodes on average lasted $63.8( \pm 21.5)$ seconds under saline treatment, in contrast under SubC inhibition cataplexy episodes lasted $45.3( \pm 9.4)$ seconds (t-test $p=0.36)$. The significant $75 \%$ decrease in the 
A

Saline

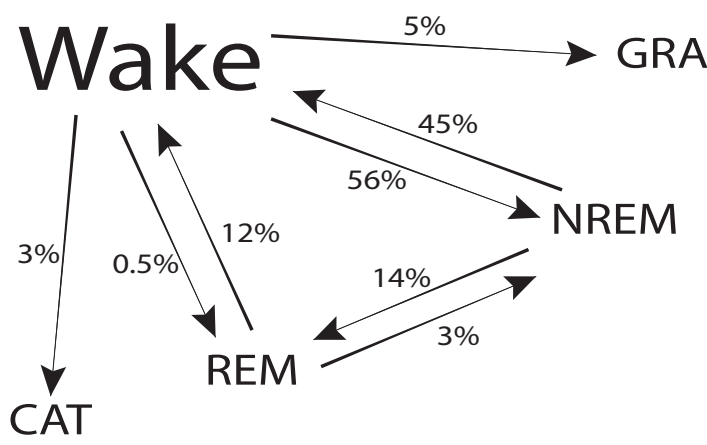

B

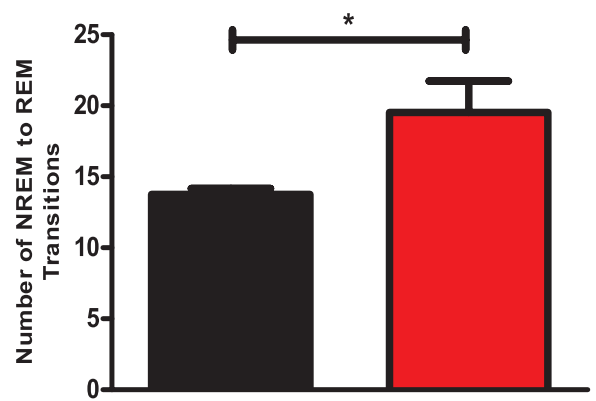

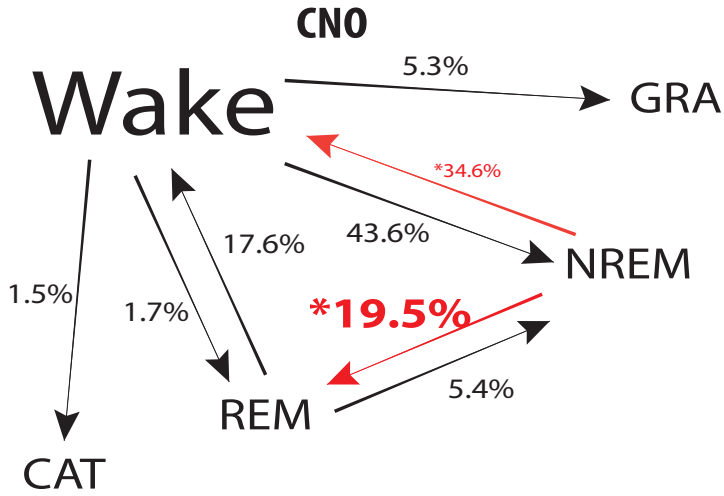

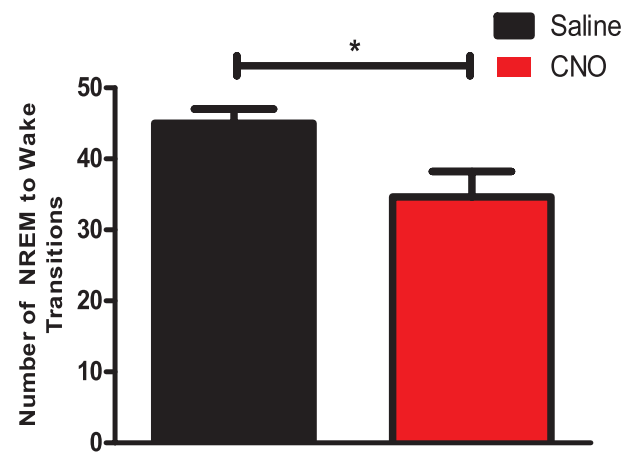

Figure 10 - Under SubC inhibition NREM sleep preferentially transitions into REM sleep at the expense of wake. A) schematic showing overall changes in state transitions under SubC inhibition. B) There are significantly more NREM to REM transitions and significantly fewer NREM to Wake transitions CNO $(10 \mathrm{mg} / \mathrm{kg})(\mathrm{t}$-test $\mathrm{P}<0.05)$ 
A

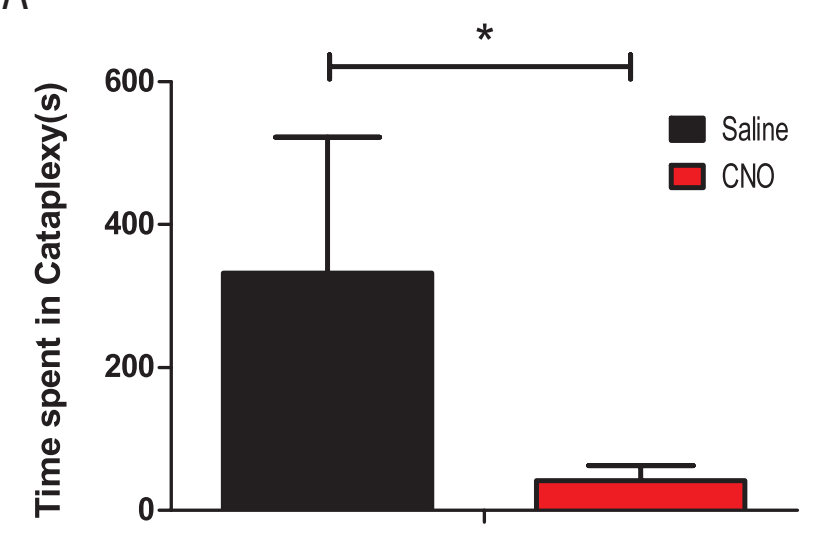

C

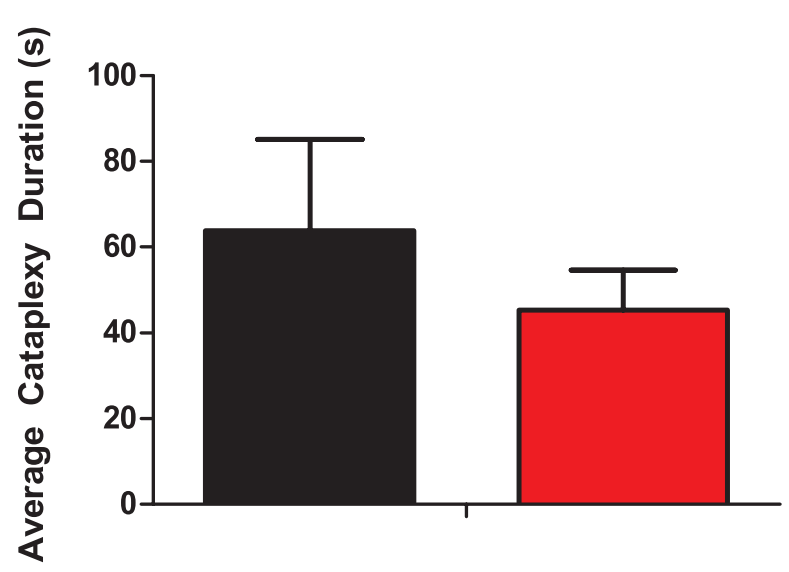

B

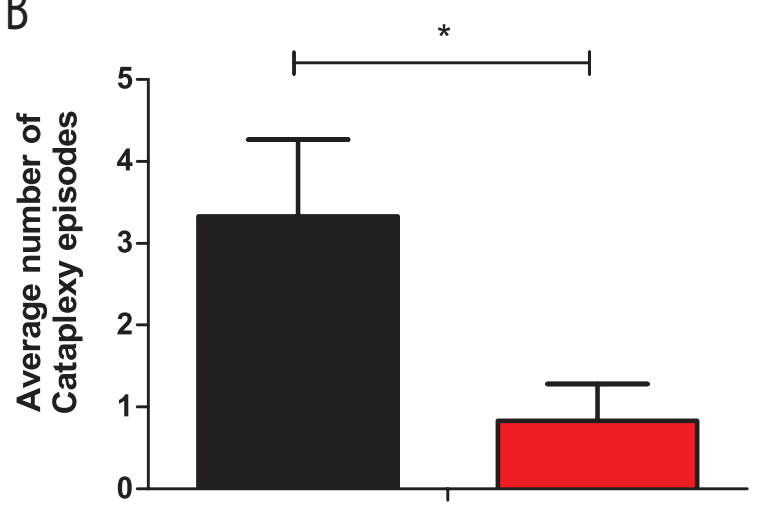

D

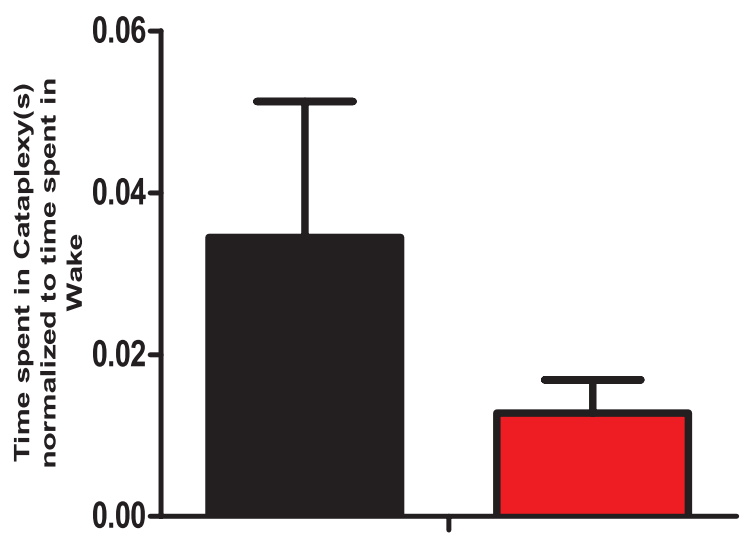

Figure 11- There is an overall decrease in cataplexy which can be accounted for by the decrease in total wake. A) Overall there is a decrease in the amount of time spent in cataplexy ( $t$-test, $p=0.04$ ), and number of cataplectic attacks ( $t$-test, $p=0.02$ ). B) Less cataplexy is observed under SubC inhibition due less opportunity to enter cataplexy from total wake. There is no difference in time spent in cataplexy after normalization to total wake (t-test $\mathrm{p}=0.13$ ). $\mathrm{CNO}(10 \mathrm{mg} / \mathrm{kg})$. 
number of cataplexy episodes indicates that the inhibition of the SubC effects cataplexy triggering mechanism rather than cataplexy maintaining mechanism.

Cataplexy is a phenomenon which occurs only during waking. Our intervention decreased the amount of time spent in wake, and therefore it is possible that the alteration observed decline in cataplexy was a result of less time spent in wakefulness. In other words our manipulation led to less opportunity to enter cataplexy. To account for the lowered levels of wakefulness, time spent in cataplexy was normalized to the time spent in wakefulness using a ratio (time spent in cataplexy in seconds)/ (time spent in wakefulness in seconds) during the first two hours post injection. For every second spent in wakefulness saline treated mice spent 0.031 ( \pm 0.012) seconds in cataplexy. Whereas, under SubC inhibition every second spent in wakefulness corresponded to $0.012( \pm 0.004)$ seconds in cataplexy (Figure 11D). After accounting for the decrease time spent in sleep, the 64.7\% decrease in cataplexy observed after SubC inhibition was no longer significant. These results indicate that inhibition of the SubC lowers levels of cataplexy; these effects may be secondary to an overall effect of SubC inhibition leading to lower levels of wake.

Section 4.8 - Inhibiting the SubC leads to a loss of normal muscle tone suppression during $\underline{\text { REM sleep, but not Cataplexy. }}$

The SubC has been postulated as a regulator of the motor atonia characteristic of REM sleep; we aimed to verify this claim. Also this investigation aimed to determine if this REM atonia centre is implicated in the loss of muscle tone seen in cataplexy. To investigate alterations in the motor profile we separated muscle activity during REM sleep into tonic and phasic (or twitch) portions. Cataplexy motor profile was analyzed looking only at tonic portion, as phasic events are not characteristic of cataplexy (figure 1). It was observed that under SubC silencing, 
A
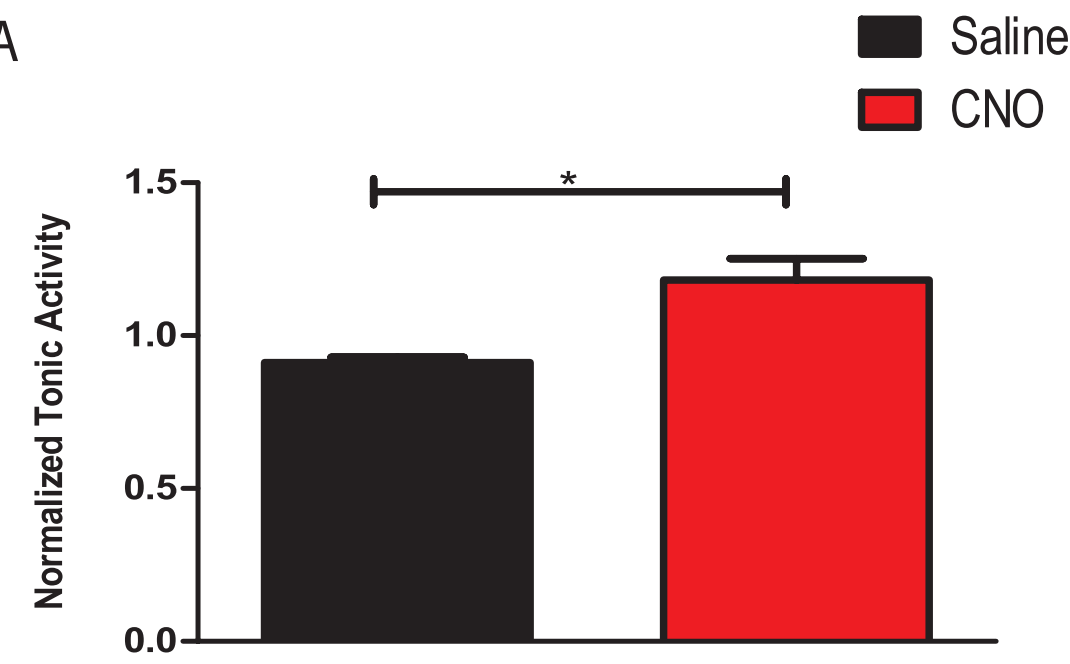

B
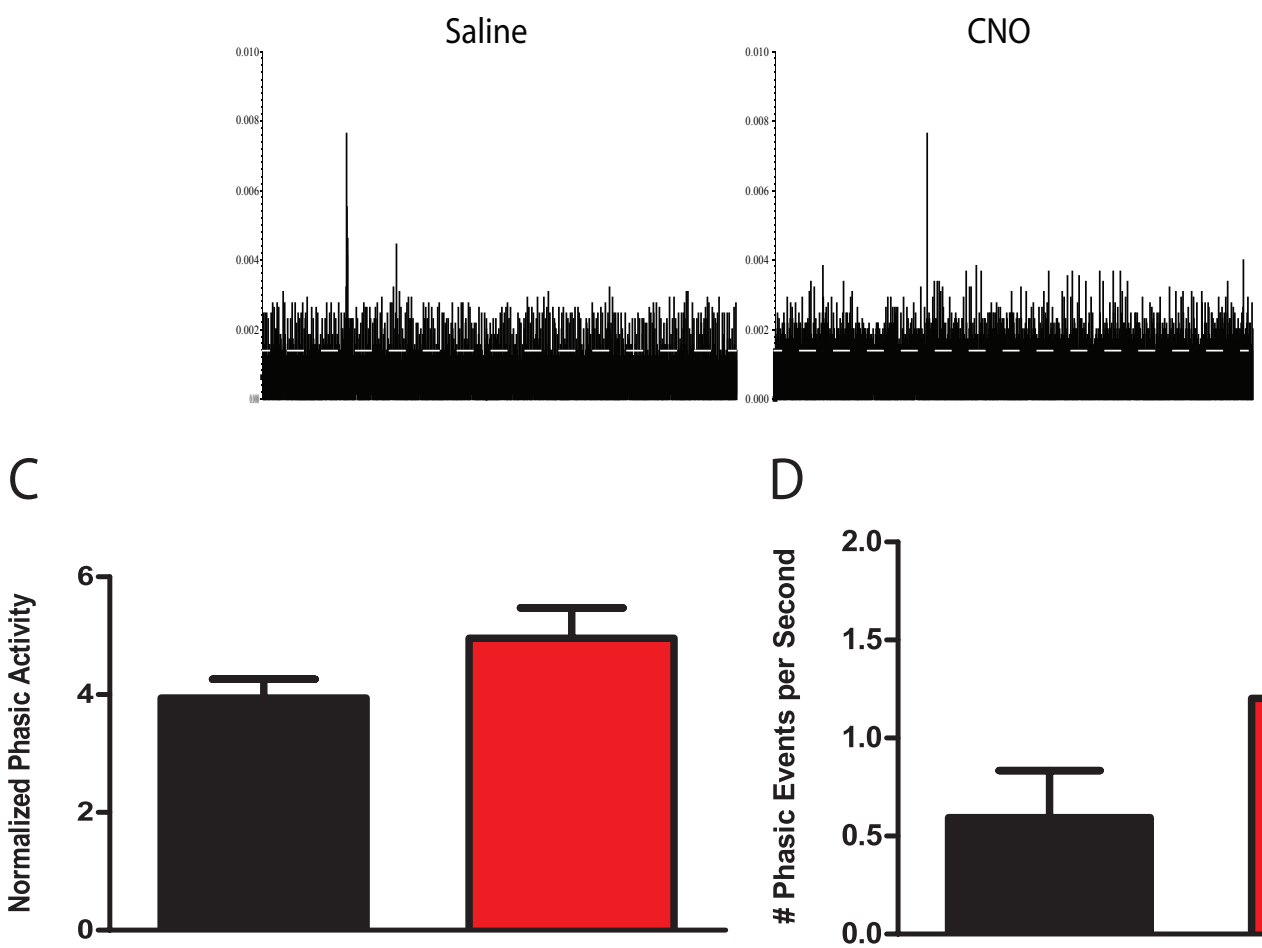

D

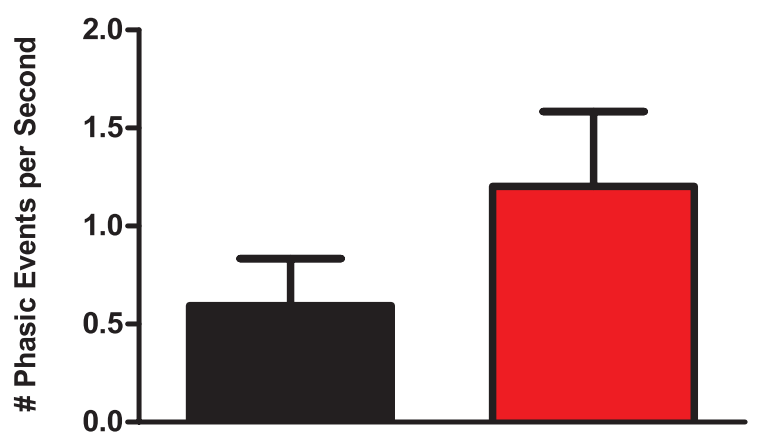

Figure 12. Inactivation of the SubC leads to REM sleep specific changes to motor tone (a loss of REM sleep atonia). (A) Silencing of the SubC leads to an loss of muscle atonia (B) Raw trace representing 30 seconds at the start of a REM episodes under saline and CNO injection. (C-D) SubC inhibition does not effect phasic properties of REM sleep. 
REM sleep tonic nuchal activity increased from 0.91 0.02 AU under saline, to $1.18 \pm 0.07$ AU (t-test $\mathrm{P}=0.009)$ (figure 12A).

Although silencing of the SubC led to a loss of REM sleep muscle tone suppression, no corresponding effect was observed for REM sleep phasic muscle activity. Under saline injection the amplitude of phasic events during REM sleep was $3.94 \pm 0.32$ AU, under SubC inhibition the amplitude of phasic events was $4.956 \pm 0.5142 \mathrm{AU}$ (t-test $\mathrm{p}=0.14$ ) (figure 12). Inhibition of the SubC did not affect the number of phasic event either. Under saline injection there were 0.59 \pm 0.23 phasic events per second, whereas under SubC inhibition the frequency of phasic events was marginally higher at $1.20 \pm 0.38$ phasic events per second ( $t$-test $\mathrm{p}=0.22$ ) (figure $12 \mathrm{C}$ ). Interestingly, this loss of atonia after SubC inactivation was not seen during the cataplexy episodes. Under saline injection, neck tonic activity was $1.30 \pm 0.22$ AU during cataplexy, whereas after SubC inhibition levels reach were not significantly greater $1.42 \pm 0.23 \mathrm{AU}$ (t-test $\mathrm{p}=0.7101$ ) (Figure 13). These results support the existing view that cells of the SubC play a crucial role in maintaining REM sleep atonia, however inhibiting these cells does not alter phasic aspects of REM sleep or tonic aspects of cataplexy.

The common conception of cataplexy as the manifestation of REM sleep during waking is predicated on the fact that in both states there is a loss of muscle tone. However it had yet to be confirmed if the motor atonia observed during cataplexy was of the same magnitude of the motor atonia observed during REM sleep. To determine if these atonia levels are comparable, the amplitude of tonic nuchal muscle activity during both REM sleep and cataplexy was compared. It was observed that the amplitude of tonic activity did not differ between REM sleep $(0.91 \pm 0.02 \mathrm{AU})$ and Cataplexy $(1.21 \pm 0.28 \mathrm{AU})$ (t-test, $\mathrm{P}=0.1233)$ (Figure 13). Since the levels of atonia are indistinguishable between periods of cataplexy and REM sleep, findings support the view that cataplexy and REM sleep may share atonia-mediating circuitry. 
A
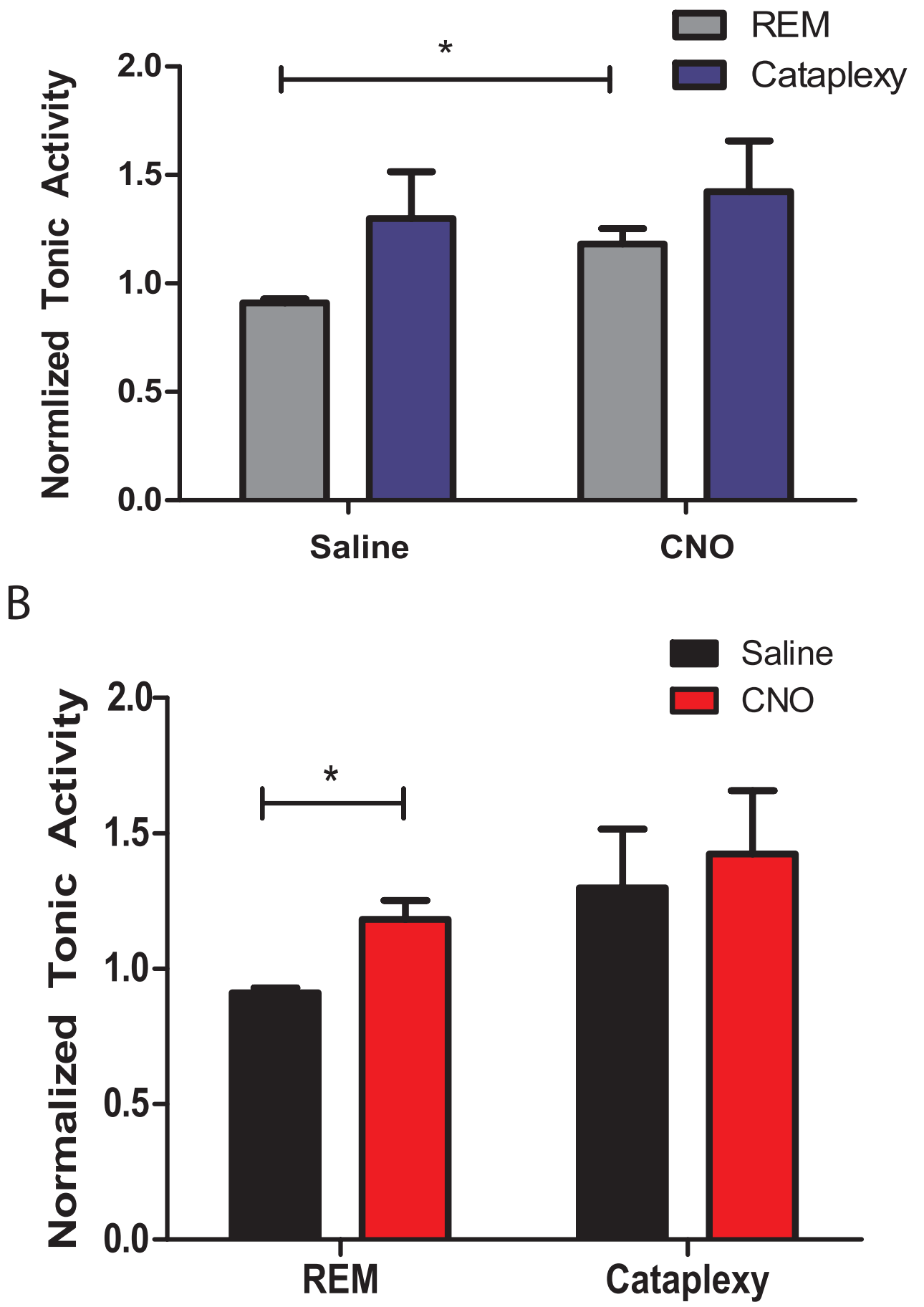

Figure 13 - SubC inhibition has causes a loss of atonia in REM sleep, but not during Cataplexy. A) Tonic muscle activity of the neck does not differ between cataplexy and REM sleep (t-test, $\mathrm{P}>0.05$ ) B) SubC inactivation does not alter muscle activity cataplexy. 
Silencing of the SUBC does not alter the stereotypic drop in nuchal muscle tone which is experienced at cataplexy onset, nor does it alter the nuchal muscle tone rebound after cataplexy (figure 14). Overall neck muscle tone drops to $31.1 \%( \pm 7.38 \%)$ of preceding active wake levels during cataplexy in the saline group; under CNO this drop is $46.9 \%( \pm 10.8)$ (2way ANOVA, $\mathrm{P}$ $>0.05)$. After the cataplexy episodes neck muscle tone increases back to $94.1 \%( \pm 11.3 \%)$ and $102.0 \%( \pm 15.5 \%)$ under saline and CNO respectively (2way ANOVA, P > 0.05). This finding indicates that factors outside of the SubC-inhibitory premotor neuron-motor pool pathway contribute to the loss of motor tone observed in cataplexy.

Section 4.9 - Inhibiting the SubC does not alter muscle tone in Wake or NREM.

To ensure that CNO inhibition of the SubC was inducing REM sleep specific motor alterations, and not altering motor levels across the sleep wake architecture, overall muscle tone was analysed during active wake, quiet wake, and NREM sleep. This was done by taking overall nuchal muscle tone in each animal during saline and CNO injection and normalizing these values back to levels observed during baseline. For example, to calculate normalized muscle activity during active wake under saline, a ratio of (muscle activity during active wake under saline/ muscle activity during active wake at baseline).

The findings confirmed that SubC inhibition did not lead to motor profile changes to states other than REM sleep. During active wake normalized overall nuchal muscle activity was 0.92 $\pm 0.11 \mathrm{AU}$ under saline, compared to $0.89 \pm 0.11 \mathrm{AU}$ under SubC inhibition (t-test $\mathrm{p}>0.05$ ). During quiet wake overall normalized nuchal muscle activity was $1.17 \pm 0.16 \mathrm{AU}$ under saline treatment, compared to $1.12 \pm 0.14$ under SubC inhibition (t-test $\mathrm{p}>0.05$ ). Finally during NREM sleep overall normalized nuchal muscle activity was $1.18 \pm 0.17 \mathrm{AU}$ under saline, compared to 


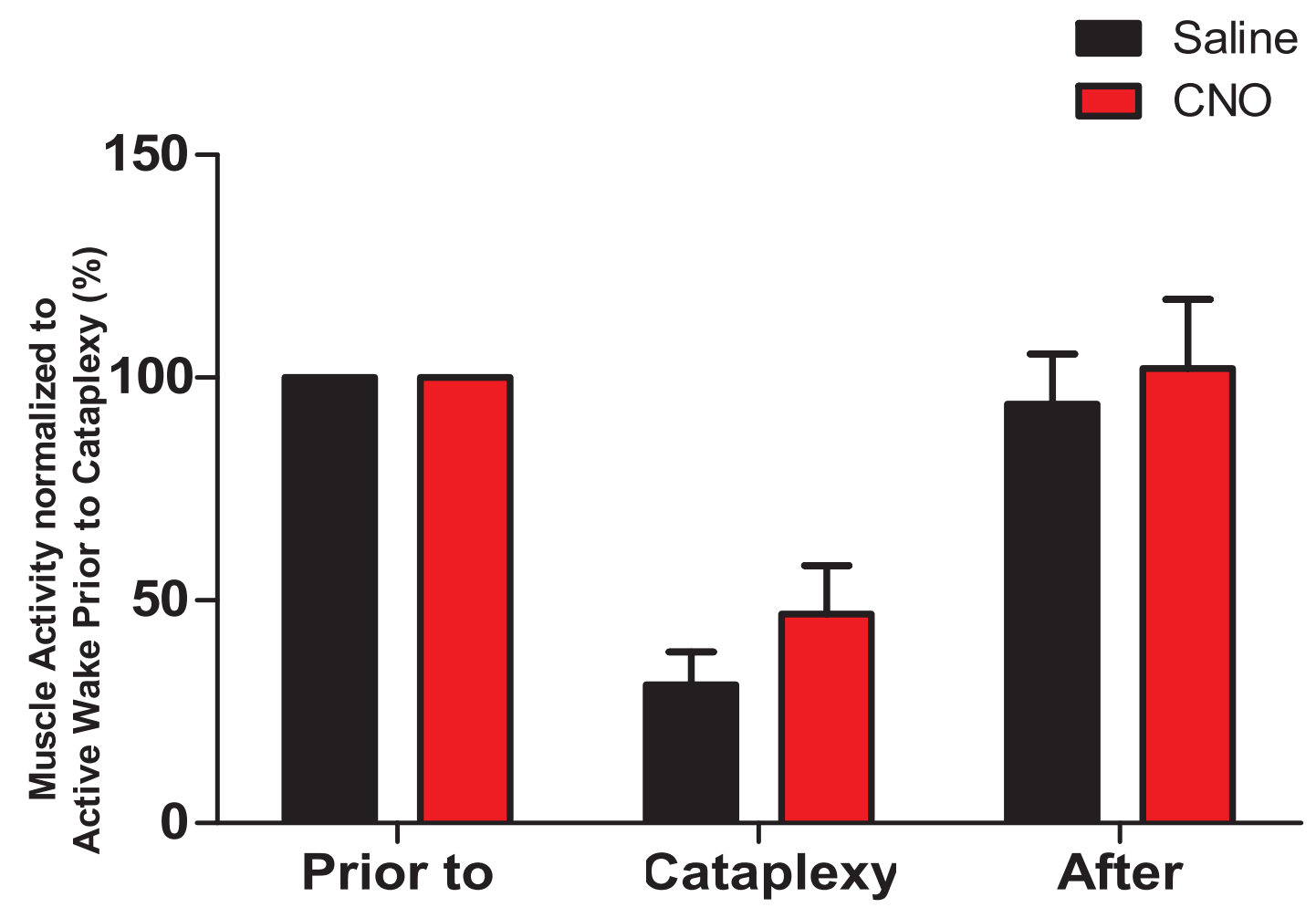

Figure 14 - Inhibition of the SubC does not alter the stereotypic motor profile of cataplexy. There is no significant change to nuchal motor activity before, during or after a cataplectic attack (t-test, $\mathrm{P}>0.05$ ) 
1.16 $\pm 0.11 \mathrm{AU}$ under SubC inhibition (t-test $\mathrm{p}>0.05$ ) (figure 15). This indicates that inhibiting the SubC does not lead to an alteration to overall motor behavior.

Section 4.10 - Inhibiting the SubC leads to greater cortical theta during REM sleep

REM sleep is a phenomenon of paradoxical high cortical activity during muscle and overall behavior inactivity. Increases to theta rhythm has been used an indicator of REM sleep intensity [60]. To investigate if SubC inactivation altered the cortical manifestation of REM sleep EEG spectral analysis was conducted. Over the three hour post injection period overall cortical EEG spectrum was not altered in the delta ${ }_{(1.01-4.06 \mathrm{~Hz})}$, theta ${ }_{(4.5-8.6 \mathrm{~Hz})}$, sigma $(9.15-14.24$ $\mathrm{Hz}$, and beta $(14.75-30.00 \mathrm{~Hz})$ EEG bands (figure 16A). However, overall EEG spectrum of the highest frequency band, Gamma $(30.54-66.12 \mathrm{~Hz})$ was significantly increased after SubC inhibition. In the saline control group, Gamma frequency compromised only $0.94 \pm 0.02 \%$, whereas after SubC inhibition this power band composed $3.3 \pm 0.6 \%$ of the power spectrum (t-test, $\mathrm{P}=0.0088$ ).

When looking specifically at REM sleep, changes to EEG spectra began to emerge (Figure 16B). During REM sleep periods there was a statistically significant increase in the predominance of theta rhythm ${ }_{(4.5-8.6 \mathrm{~Hz})}$ from $51.2 \pm 0.4 \%$ under saline to $56.3 \pm 0.3$ under SubC inhibition (t-test $\mathrm{P}=0.002)$. An increase theta rhythm has been used an indicator of REM sleep intensity [60]. Therefore inhibition of the SubC leads to increased intensity of REM sleep, through its increase in theta rhythm. REM sleep is also characterized by lower levels of delta rhythm. Inhibition of the SubC shows a significant decrease in delta $(1.01-4.06 \mathrm{~Hz})$ frequency. Under saline delta rhythm makes up $19.51 \pm 0.3 \%$ of the spectral band, whereas under SubC inhibition, delta rhythm only makes up $13.49 \pm 0.013 \%$ (t-test $\mathrm{P}<0.001$ ) (figure 16B). An 


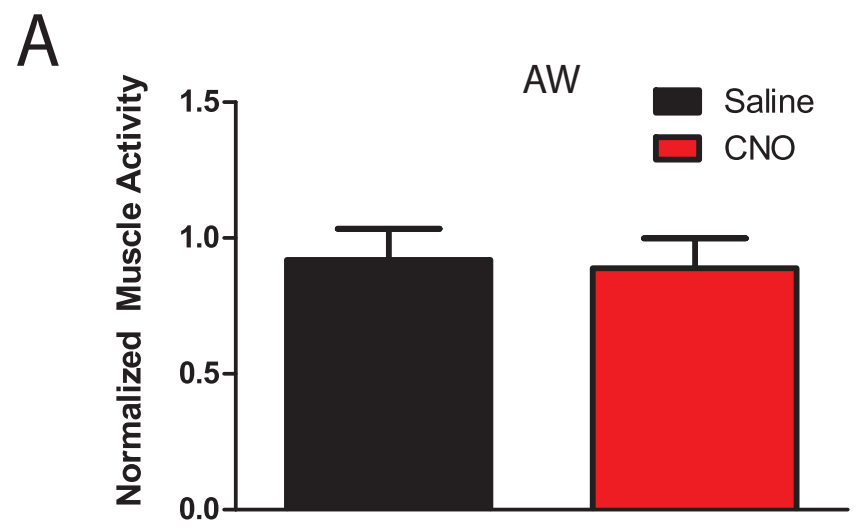

B
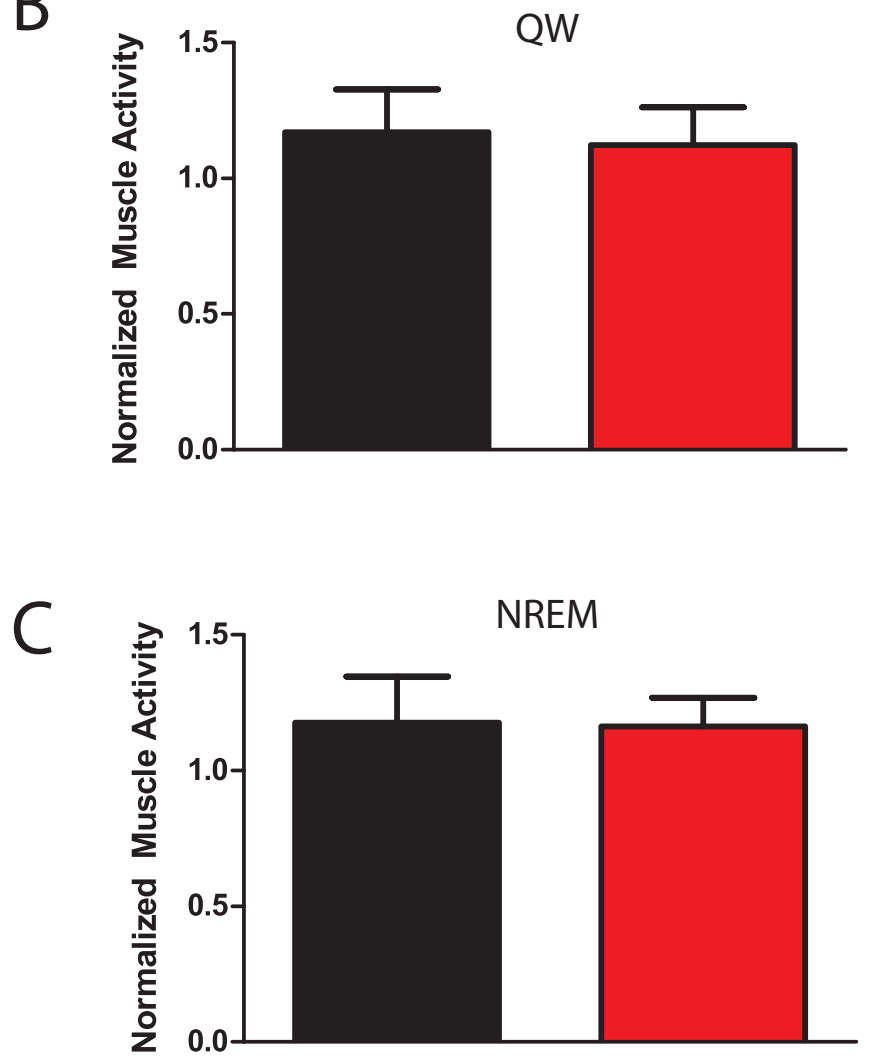

Fig 15 - Inhibition of SubC does not alter motor profile outside of REM sleep. There is no effect of SubC silencing on muscle activity in active wake, quiet wake and NREM sleep. $\mathrm{CNO}(10 \mathrm{mg} / \mathrm{kg})\left({ }^{*}\right.$-test $\mathrm{P}<0.05$ ) 
increase in Gamma rhythm $(30.54-66.12 \mathrm{~Hz})$ is also observed (saline: $1.01 \pm 0.4 \%$ and CNO 3.3 \pm 0.02; t-test $\mathrm{P}<0.001)$. 

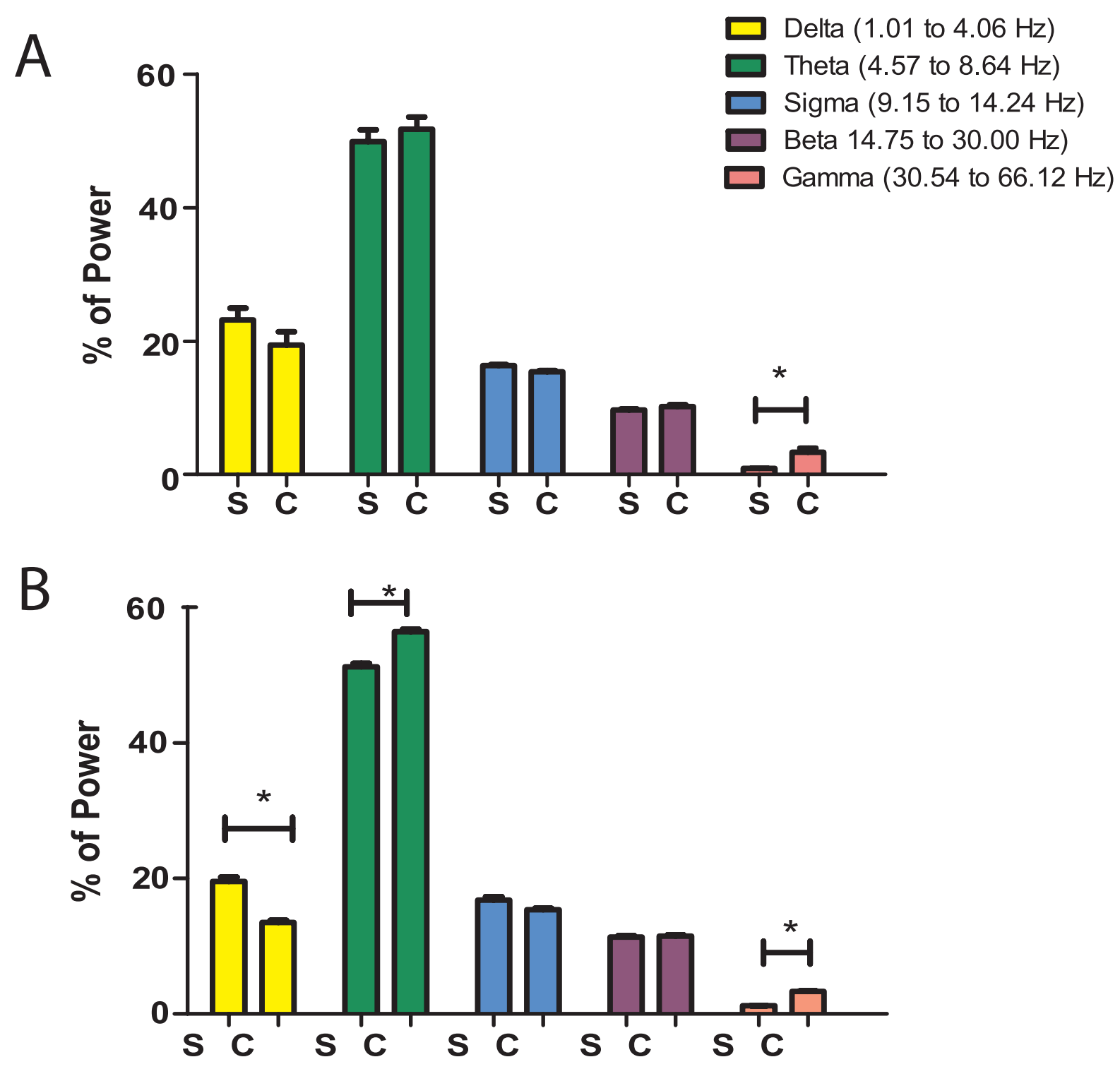

Figure 16 - Inhibiting the SubC leads to profound changes cortical power spectrum during REM sleep. A) Under SubC inhibition there is an overall spectral power is increased in gamma. B) During REM sleep SubC inhibition retains the higher gamma, but also shows a decrease in delta and an increase in theta rhythm. $\mathrm{S}=$ saline, $\mathrm{C}=\mathrm{CNO}(10 \mathrm{mg} / \mathrm{kg})(\mathrm{t}$-test $\mathrm{p}<0.05)$ 


\section{$\underline{\text { Section } 5 \text { - Discussion }}$}

\section{Section 5.1 - Overview}

At first glance it may seem paradoxical that our intervention to inhibit the REM-ON neurons of the SubC would lead to more REM sleep. Under the reciprocal flip-flop switch, activation of glutamatergic SubC neurons leads to the cortical and motor aspects of REM sleep. REM is gated by GABAergic input from the REM-off VLPAG. According to this model, during wake and NREM the VLPAG is active and sending inhibitory GABAergic signals on to the glutamatergic REM-ON neurons of the SubC. Conversely, during REM the VLPAG is inactive, and inhibition onto the SubC is removed. The evidence presented here is not in agreement with aforementioned model, as inhibition of SubC does not lead to REM sleep. This evidence forces us to re-examine our understanding of how the SubC controls REM sleep.

Not only did the mouse spend more time in REM sleep, it also displayed increased REM sleep intensity (increased cortical theta power, and decreased delta power) (figure 16). Despite these REM sleep promoting aspects of SubC inhibition one REM sleep feature, atonia, was lost. Inhibiting all neurons of the SubC led to contrasting effects on the cortical and motor aspects of REM sleep. Therefore activity of SubC subpopulations must be under separate control. Our results indicate cortical theta is caused by inhibiting the SubC, while REM atonia is due to exciting the SubC.

Inhibiting the neurons of the SubC led to disruptions to REM sleep atonia. A focus of this thesis was to determine if REM sleep atonia is activated during wakefulness to cause cataplexy. Since, our intervention removed of REM sleep atonia; we would hypothesize less cataplexy as well. Indeed, fewer cataplexy episodes were observed, with the mouse spending 
less time in cataplexy (figure 11). Unexpectedly, however, SubC inhibition does not alter the amplitude of motor activity during cataplexy (figure 13).

My thesis aimed to test if cataplexy and REM sleep shared common neural mechanisms. In doing in doing so contributions were made to understanding the mechanisms which underlie the SubC's role in REM sleep generation. This discussion will highlight how these findings factor into the glutamatergic/GABAergic flip-flop switch and reciprocal inhibition cholinergicmonoaminergic models of REM sleep. I will then discuss how these data provide insight into the role of REM sleep mechanisms in cataplexy. Lastly I will discuss some technical consideration, limitations to this study and future directions for this research.

These findings are not consistent with the current the gabaergic/glutamatertic flip flop hypothesis of REM sleep generation. It would be expected that administration of HM4Di would mimic the inhibitory drive of the VLPAG on the SubC. Under the flip-flop model the VLPAG shuts off during REM sleep; this frees the SubC from GABAergic inhibition and leads to REM sleep. Therefore according to this model what we would expect with CNO administration would be a reduction of both REM sleep parameters postulated to be under SubC control: (a) an abolishment of REM sleep atonia (b) a lack of cortical theta. What we observe is only REM sleep atonia is reduced. Cortical theta and REM sleep in general is significantly greater under the SubC inhibition. These findings provide evidence that (1) the motor atonia SubC neurons are REM-ON, and (2) cortical SubC neurons are actually REM-OFF. Therefore one inhibitory GABAergic drive is not sufficient to account for the complexity of SubC circuitry. Although these findings do not rule out the role of GABAergic mechanisms at the SubC in REM sleep, these findings refute the claim that inhibitory GABAergic mechanisms are the sole gatekeeper of REM sleep. 
These findings are in agreement with the cholinergic model presented by Sakai in 1979. Under this model there are two populations of the SubC which respond differently to acetylcholine agonists (carbachol). A first population excited by ACh, activating neurons which innervate inhibitory pre-motor neurons leading to REM sleep atonia. A second population inhibited by ACh, silencing a population of neurons which innervate the thalamus leading to the promotion of theta rich cortical activity.

The SubC was postulated to respond differently to the same ligand because these two populations were believed to express different receptors. The REM atonia population would contain high levels of M1/M3 AcH receptors which work along the g(q)-coupled protein pathway modulating intracellular calcium to lead to burst-firing of neurons. Whereas, the cortical theta population would contain high levels of M2/M4 AcH receptors which work along the g(i/o)-coupled protein pathway leading to activation of G-protein inwardly rectifying potassium (GIRK) channels.

This hypothesis elegantly accounts for the empirical data presented here. Incorporation of the HM4Di receptor would lead to a new, inhibitory signal in the M3 expressing REM atonia SubC population. During REM sleep this new inhibitory drive would silence, otherwise active SubC neurons, leading to a loss of muscle atonia. Addition of HM4Di into the cortical regulating neurons of the SubC, would mimic the native actions of M2/M4 on these neurons; leading to heightened cortical theta during sleep, and thus greater levels of REM sleep.

Section 5.2 - Do cataplexy and REM sharing common mechanism?

Inhibition of the REM sleep generating SubC reduced the occurrence cataplexy. This finding supports the view that REM sleep and cataplexy share common mechanism. It appears that the atonia observed during cataplexy is mediated through the SubC atonia pathway. A 
circuit begins to emerge, where cataplexy is triggered in an unknown region. Excitation of SubC neurons responsible for motor atonia neurons leads to depolarization of inhibitory premotor neurons of the ventral medial medulla neurons (GiV) and/or inhibitory spinal interneurons. This leads to inhibitory GABA and glycine release onto the motor poor leading to loss of muscle tone. This supports the view that the paralysis observed during cataplexy is due to activation of REM sleep atonia circuitry.

These findings are supported by a large body of evidence which pointing to acetylcholine as an important neurotransmitter system for cataplexy. In narcoleptic dogs increasing cholinergic drive systemically and focally into pontine regions regulating REM sleep atonia increase cataplexy; these findings have been recently reproduced and built upon in narcoleptic mice[36-38]. Our findings compliment these prior studies. Incorporating an HM4di receptor into the atonia producing neurons of the SubC, effectively cutting the REM sleep atonia pathway, leads to decreases in cataplexy. In conclusion, our findings indicate that REM sleep atonia mechanisms are critical to the manifestation of cataplexy.

Section 5.3 - Technical limitations and Future directions

The first step to build on the findings of this thesis would be the incorporation of HM3Dq into the neurons of the SubC. I would hypothesize that incorporation of HM3Dq receptors into the SubC would lead to dysfunction of the cortical theta pathway, leaving REM atonia intact or heightened. If observed, those findings along with the evidence provided in this thesis would provide strong evidence for the Sakai model of Cholinergic REM sleep control.

All findings presented here are from a transgenic mouse line which lacks a functional hypocretin system, a key neurotransmitter for sleep-wake regulation. These findings cannot yet be extrapolated to determine normal REM sleep regulation. An essential investigation to 
broaden our interpretation would be to conduct all studies in regular wild-type mice to confirm the observed changes to REM sleep regulating mechanisms.

This study has been a first-pass investigation to determine if pharmacosynthetic inhibition of SubC can alter cataplexy manifestation. In order to avoid the lengthy process of deriving hypocretin knockout mice with targeted CRE expression, we used an AAV vector not driven by a cre-lox system. This resulted in non-specific HM4di incorporation into the region of SubC. Apart from stereotaxic targeting of AAV injection, there is no way of preventing expression of HM4Di in neighboring regions. The SubC is neighbored by many cell groups critical to sleep wake promotion such as the locus coeruleus, laterodorsal tegmental nucleus, pedunculopontine tegmental nucleus and the parabrachial nucleus. Non-specific expression, and could have effects on nearby wake promoting groups contributing to our findings of increased somnolence. To account for this limitation, subsequent studies will require specific inhibition of the SubC region. This can be done using a FLEX-AAV and require a double transgenic, hypocretin knockout with CRE expression in specific neurotransmitter groups. This model will allow us to not only target the SubC, but also decipher the role of the glutamatergic and gabaergic sub-populations of the SubC.

In the literature, the SubC has not been a well described area in the mouse. Our understanding of which neurons encompass this group are based on two sets of studies. Unfortunately these groups are not in full agreement with the location of the SubC in mice. Jun Lu's group out of Harvard determined the location of the SubC in rodents involves retrograde tracing from only the ventral horn of the spinal cord[32]. This technique could lead to sampling bias because it misses the projections of the SubC onto brainstem pre-motor neuronal groups such as the GiA and GiV. Lending credence to this thought, a distinct neuroanatomical 
coordinate for the SubC in mice was determined using FOS studies of REM-ON neurons (unpublished data).

DREADDs is a novel technique and broad implications must be made with caution. To

claim HM3Dq activates neurons, and HM4Di inhibits neurons would be a gross generalization. It has been shown that M3-muscarinic receptor is differentially phosphorylated in the cortex, hippocampus, pancreas and salivary glands. The investigators behind these studies claim

"Signalling outcome of a particular receptor subtype can be tailored to meet the physiological requirements of that receptor. In this way, the same receptor subtype can be expressed in different tissue types and mediate an array of physiological functions, in part, by adopting different patterns of phosphorylation and thereby different signalling profiles" [61].

Therefore before broader implications can be made, confirmation by invivo cell recording that HM4Di leads to inhibition the neurons of the SubC is required.

Section 5.4 - $\underline{\text { Concluding Remarks }}$

From the earliest findings of von Economo, through the work of Jouvet, Hobson, McCarley, Saper and many others the SubC has been classified as a critical region for REM sleep manifestation. This thesis provides a small contribution to the vast collection of work investigating REM sleep and cataplexy. With the advent of more refined bioengineered tools such as optogenetics and pharmacogenetics, this generations contributions hope to provide great advances in solving of the enduring mystery of modern neuroscience, the mystery of sleep. 


\section{Section 6 - References}

1. Demetriades, A.K., From encephalitis lethargica to cerebral cytoarchitectonics: the polymath talent of Constantin von Economo (1876-1931), pioneer neuroanatomist, neurophysiologist and military aviator. Scott Med J, 2012. 57(4): p. 232-6.

2. Schenck, C.H., et al., English translations of the first clinical reports on narcolepsy and cataplexy by Westphal and Gelineau in the late 19th century, with commentary. J Clin Sleep Med, 2007. 3(3): p. 301-11.

3. Peyron, C., et al., Neurons containing hypocretin (orexin) project to multiple neuronal systems. J Neurosci, 1998. 18(23): p. 9996-10015.

4. Donadio, V., et al., Sympathetic and cardiovascular activity during cataplexy in narcolepsy. J Sleep Res, 2008. 17(4): p. 458-63.

5. $\quad$ Siegel, J.M., et al., Heart rate and blood pressure changes associated with cataplexy in canine narcolepsy. Sleep, 1986. 9(1 Pt 2): p. 216-21.

6. Aserinsky, E. and N. Kleitman, Regularly occurring periods of eye motility, and concomitant phenomena, during sleep. Science, 1953. 118(3062): p. 273-4.

7. Jouvet, M., [Research on the neural structures and responsible mechanisms in different phases of physiological sleep]. Arch Ital Biol, 1962. 100: p. 125-206.

8. Sakai, K., et al., [Localization of cholinergic neurons in the cat lower brain stem]. C R Acad Sci III, 1986. 303(8): p. 317-24.

9. Siegel, J.M., R. Nienhuis, and K.S. Tomaszewski, REM sleep signs rostral to chronic transections at the pontomedullary junction. Neurosci Lett, 1984. 45(3): p. 241-6.

10. Boissard, R., et al., The rat ponto-medullary network responsible for paradoxical sleep onset and maintenance: a combined microinjection and functional neuroanatomical study. Eur J Neurosci, 2002. 16(10): p. 1959-73.

11. Lu, J., et al., A putative flip-flop switch for control of REM sleep. Nature, 2006. 441(7093): p. 589-94.

12. Hobson, J.A., R.W. McCarley, and P.W. Wyzinski, Sleep cycle oscillation: reciprocal discharge by two brainstem neuronal groups. Science, 1975. 189(4196): p. 55-8.

13. Gervasoni, D., et al., Effect of chronic treatment with milnacipran on sleep architecture in rats compared with paroxetine and imipramine. Pharmacol Biochem Behav, 2002. 73(3): p. 557-63. 
14. Jones, B.E., Paradoxical sleep and its chemical/structural substrates in the brain. Neuroscience, 1991. 40(3): p. 637-56.

15. Sakai, K. and Y. Koyama, Are there cholinergic and non-cholinergic paradoxical sleepon neurones in the pons? Neuroreport, 1996. 7(15-17): p. 2449-53.

16. Deurveilher, S., B. Hars, and E. Hennevin, Pontine microinjection of carbachol does not reliably enhance paradoxical sleep in rats. Sleep, 1997. 20(8): p. 593-607.

17. Gnadt, J.W. and G.V. Pegram, Cholinergic brainstem mechanisms of REM sleep in the rat. Brain Res, 1986. 384(1): p. 29-41.

18. Gnadt, J.W., G.V. Pegram, and J.F. Baxter, The acetylcholinesterase inhibitor diisopropyl-fluorophosphate increases REM sleep in rats. Physiol Behav, 1985. 35(6): p. 911-6.

19. Shiromani, P.J. and W. Fishbein, Continuous pontine cholinergic microinfusion via mini-pump induces sustained alterations in rapid eye movement (REM) sleep. Pharmacol Biochem Behav, 1986. 25(6): p. 1253-61.

20. Velazquez-Moctezuma, J., J.C. Gillin, and P.J. Shiromani, Effect of specific M1, M2 muscarinic receptor agonists on REM sleep generation. Brain Res, 1989. 503(1): p. 12831.

21. Sakai, K. and P.C. Neuzeret, Brainstem neurons responsible for postural, masseter or pharyngeal muscle atonia during paradoxical sleep in freely-moving cats. Arch Ital Biol, 2011. 149(4): p. 325-47.

22. Sakai, K., et al., Tegmentoreticular projections with special reference to the muscular atonia during paradoxical sleep in the cat: an HRP study. Brain Res, 1979. 176(2): p. 233-54.

23. Brown, R.E., et al., Electrophysiological characterization of neurons in the dorsolateral pontine rapid-eye-movement sleep induction zone of the rat: Intrinsic membrane properties and responses to carbachol and orexins. Neuroscience, 2006. 143(3): p. 73955.

24. Guyenet, P.G. and G.K. Aghajanian, ACh, substance P and met-enkephalin in the locus coeruleus: pharmacological evidence for independent sites of action. Eur J Pharmacol, 1979. 53(4): p. 319-28.

25. Koyama, Y. and Y. Kayama, Mutual interactions among cholinergic, noradrenergic and serotonergic neurons studied by ionophoresis of these transmitters in rat brainstem nuclei. Neuroscience, 1993. 55(4): p. 1117-26.

26. Luppi, P.H., et al., The nuclei of origin of monoaminergic, peptidergic, and cholinergic afferents to the cat nucleus reticularis magnocellularis: a double-labeling study with cholera toxin as a retrograde tracer. J Comp Neurol, 1988. 277(1): p. 1-20. 
27. Luppi, P.H., et al., The neuronal network responsible for paradoxical sleep and its dysfunctions causing narcolepsy and rapid eye movement (REM) behavior disorder. Sleep Med Rev, 2011. 15(3): p. 153-63.

28. Clement, O., et al., The lateral hypothalamic area controls paradoxical (REM) sleep by means of descending projections to brainstem GABAergic neurons. J Neurosci, 2012. 32(47): p. 16763-74.

29. George, R., W.L. Haslett, and D.J. Jenden, A Cholinergic Mechanism in the Brainstem Reticular Formation: Induction of Paradoxical Sleep. Int J Neuropharmacol, 1964. 3: p. 541-52.

30. Anaclet, C., et al., Brainstem circuitry regulating phasic activation of trigeminal motoneurons during REM sleep. PLoS One, 2010. 5(1): p. e8788.

31. Luppi, P.H., et al., Paradoxical (REM) sleep genesis: the switch from an aminergiccholinergic to a GABAergic-glutamatergic hypothesis. J Physiol Paris, 2006. 100(5-6): p. 271-83.

32. Krenzer, M., et al., Brainstem and spinal cord circuitry regulating REM sleep and muscle atonia. PLoS One, 2011. 6(10): p. e24998.

33. Overeem, S., et al., Narcolepsy: clinical features, new pathophysiologic insights, and future perspectives. J Clin Neurophysiol, 2001. 18(2): p. 78-105.

34. Sasai, T., et al., Comparison of clinical characteristics among narcolepsy with and without cataplexy and idiopathic hypersomnia without long sleep time, focusing on HLA-DRB1( *)1501/DQB1( *)0602 finding. Sleep Med, 2009. 10(9): p. 961-6.

35. Siegel, J.M., et al., Neuronal activity in narcolepsy: identification of cataplexy-related cells in the medial medulla. Science, 1991. 252(5010): p. 1315-8.

36. Kalogiannis, M., et al., Cholinergic modulation of narcoleptic attacks in double orexin receptor knockout mice. PLoS One, 2011. 6(4): p. e18697.

37. Reid, M.S., et al., Cholinergic mechanisms in canine narcolepsy--I. Modulation of cataplexy via local drug administration into the pontine reticular formation. Neuroscience, 1994. 59(3): p. 511-22.

38. Kalogiannis, M., et al., Narcoleptic orexin receptor knockout mice express enhanced cholinergic properties in laterodorsal tegmental neurons. Eur J Neurosci, 2010. 32(1): p. 130-42.

39. Nitz, D., et al., Altered distribution of cholinergic cells in the narcoleptic dog. Neuroreport, 1995. 6(11): p. 1521-4.

40. Wu, M.F., et al., Locus coeruleus neurons: cessation of activity during cataplexy. Neuroscience, 1999. 91(4): p. 1389-99. 
41. Willie, J.T., et al., Distinct narcolepsy syndromes in Orexin receptor-2 and Orexin null mice: molecular genetic dissection of Non-REM and REM sleep regulatory processes. Neuron, 2003. 38(5): p. 715-30.

42. Carter, M.E., et al., Tuning arousal with optogenetic modulation of locus coeruleus neurons. Nat Neurosci, 2010. 13(12): p. 1526-33.

43. Nishino, S., et al., Is narcolepsy a REM sleep disorder? Analysis of sleep abnormalities in narcoleptic Dobermans. Neurosci Res, 2000. 38(4): p. 437-46.

44. Wisor, J.P., et al., Dopaminergic role in stimulant-induced wakefulness. J Neurosci, 2001. 21(5): p. 1787-94.

45. Wu, M.F., et al., Activity of dorsal raphe cells across the sleep-waking cycle and during cataplexy in narcoleptic dogs. J Physiol, 2004. 554(Pt 1): p. 202-15.

46. John, J., et al., Cataplexy-active neurons in the hypothalamus: implications for the role of histamine in sleep and waking behavior. Neuron, 2004. 42(4): p. 619-34.

47. Kaur, S., et al., Hypocretin-2 saporin lesions of the ventrolateral periaquaductal gray (vlPAG) increase REM sleep in hypocretin knockout mice. PLoS One, 2009. 4(7): p. e6346.

48. Okura, M., et al., Sulpiride, a D2/D3 blocker, reduces cataplexy but not REM sleep in canine narcolepsy. Neuropsychopharmacology, 2000. 23(5): p. 528-38.

49. Sakurai, T., Orexin deficiency and narcolepsy. Curr Opin Neurobiol, 2013.

50. Snyder, F., et al., Changes in Respiration, Heart Rate, and Systolic Blood Pressure in Human Sleep. J Appl Physiol, 1964. 19: p. 417-22.

51. Nawaratne, V., et al., New insights into the function of M4 muscarinic acetylcholine receptors gained using a novel allosteric modulator and a DREADD (designer receptor exclusively activated by a designer drug). Mol Pharmacol, 2008. 74(4): p. 1119-31.

52. Alvarez-Curto, E., et al., Developing chemical genetic approaches to explore G proteincoupled receptor function: validation of the use of a receptor activated solely by synthetic ligand (RASSL). Mol Pharmacol, 2011. 80(6): p. 1033-46.

53. Jann, M.W., Y.W. Lam, and W.H. Chang, Rapid formation of clozapine in guinea-pigs and man following clozapine-N-oxide administration. Arch Int Pharmacodyn Ther, 1994. 328(2): p. 243-50.

54. Guettier, J.M., et al., A chemical-genetic approach to study G protein regulation of beta cell function in vivo. Proc Natl Acad Sci U S A, 2009. 106(45): p. 19197-202.

55. Ray, R.S., et al., Egr2-neurons control the adult respiratory response to hypercapnia. Brain Res, 2013. 1511: p. 115-25. 
56. Li, H., et al., Experience-dependent modification of a central amygdala fear circuit. Nat Neurosci, 2013. 16(3): p. 332-9.

57. Ray, R.S., et al., Impaired respiratory and body temperature control upon acute serotonergic neuron inhibition. Science, 2011. 333(6042): p. 637-42.

58. Burgess, C.R., et al., Dopaminergic regulation of sleep and cataplexy in a murine model of narcolepsy. Sleep, 2010. 33(10): p. 1295-304.

59. Brooks, P.L. and J.H. Peever, Glycinergic and GABA(A)-mediated inhibition of somatic motoneurons does not mediate rapid eye movement sleep motor atonia. J Neurosci, 2008. 28(14): p. 3535-45.

60. Cerri, M., et al., Cold exposure and sleep in the rat: effects on sleep architecture and the electroencephalogram. Sleep, 2005. 28(6): p. 694-705.

61. Tobin, A.B., G-protein-coupled receptor phosphorylation: where, when and by whom. Br J Pharmacol, 2008. 153 Suppl 1: p. S167-76. 